\title{
Prevention and Therapy
}

JeAN-MARie LACHAPELLE, W. Wigger-Alberti, ANDERS BOMAN,

Gunh A. Mellström, Britta Wulfhorst, Meike Bock,

Christoph Skudlik, Swen Malte John, Daniel Perrenoud,

Thierry Gogniat, William Olmstead, Elisabeth Held, Tove Agner

\section{Contents}

44.1 Prevention of and Protection from Contact Dermatitis (with Special Reference

to Occupational Dermatology) . . . . . . . JeAN-Marie LaChapelle

44.1.1 Introduction: General Principles and Considerations ...........

44.1.2 Primary, Secondary, and Tertiary Prevention of Allergic Contact Dermatitis . . . . . . . .

44.1.3 Allergies to Dental Acrylates:

A Specific Example to Illustrate a Program of Prevention .............

44.1.4 Primary, Secondary, and Tertiary Prevention of Irritant Contact Dermatitis . . . . . . . 834

44.1.5 An Overview of Applicable Collective Measures of Prevention and Protection ... 835

44.1.5.1 Use of Potent Allergens in Closed Systems . 835

44.1.5.2 Automation . . . . . . . . . . . . 835

44.1.5.3 Allergen Replacement or Removal . . . . . . 835

44.1.5.4 Measures Promoting the Proper Use of Industrial Irritants or Allergens . . . . . 836

44.1.5.5 Visit of the Dermatologist to the Workplace . 837 References . . . . . . . . . 837

44.2 Skin Protection and Skin Care . . . . . 838 W. Wigger-Alberti

44.2.1 Introduction . . . . . . . . . .

44.2.2 Protection Principles . . . . . . . . . . . .

44.2.3 Proof of Efficacy . . . . . . . . . . .

44.2.4 Usage and Application . . . . . . . . . . . . . .

44.2 .5 Strategies . . . . . . . . . . . . . . . . Suggested Reading . . . . . . . . . . . .

References .............

Protective Gloves . . . . . . . . . . . . . Anders Boman, Gunh A. Mellström

44.3.1 Introduction . . . . . . . . .

44.3.2 Intended Use of Gloves . . . . . . . . . . . .

44.3.2.1 Protective Gloves . . . . . . . . . . . . . . . . .

44.3.2.2 Medical Gloves . . . . . . . . . . . . . . . . .

44.3.3 Selection Procedure . . . . . . . . . . .

44.3.3.1 Selecting Gloves to Protect Against Chemicals

44.3.3.2 Selecting Gloves

to Protect Against Microorganisms . . . . . .

44.3.4 Glove Materials and Manufacturing . . . . .

44.3.5 Testing the Protective Glove Barrier . . . . .

44.3.5.1 Standard Test Methods . . . . . . . . . .

44.3.5.2 In Vivo Testing . . . . . . . . . . .
44.3.6 Protective Effects of Gloves _. . . . . . . 850

44.3.6.1 Protection Against Microorganisms . . . . . 850

44.3.6.2 Protection Against Some Chemical Agents Hazardous to the Skin . . . . . . . . . . 851

44.3.7 Information Sources . . . . . . . . . . . . . . 852

44.3.7.1 Internet . . . . . . . . . . . . . 852

44.3.7.2 Bibliographic Data . . . . . . . . . . . 853

44.3.8 Limitations on Use Due to Side-Effects, and Therapeutic Alternatives . . . . . . . 853

44.3.8.1 Gloves Made From Synthetic Materials . . . 853

44.3.8.2 Double Gloving . . . . . . . . . . . . . . . . . . . 853

44.3.8.3 Powder-Free Gloves . . . . . . . . . . . 853

44.3.9 Conclusions . . . . . . . . . . . . . . . . . . . . 853 References ............. 854

44.4 Worker Education and Teaching Programs . 855

44.4.1 The German Experience . . . . . . . . . . 855

Britta Wulfhorst, Meike Bock, Christoph Skudlik, Swen Malte John 1

44.4.1.1 Introduction . . . . . . . . . . 855

44.4.1.2 Primary Prevention of Occupational Contact Dermatitis . . . . 855

44.4.1.3 Secondary Prevention of Occupational Contact Dermatitis . . . . 856

44.4.1.4 Tertiary Prevention of Occupational Contact Dermatitis in High-Risk Professions . . . . . 858
References . . . . . . . . . . 860

44.4.2 The Swiss Experience: www.2hands.ch . . . . 861 Daniel Perrenoud, Thierry Gogniat, William Olmstead

44.4.2.1 Introduction . . . . . . . . . . . . . 861

44.4.2.2 The Beginning . . . . . . . . . . . . . . . 861

44.4.2.3 Developing New Material . . . . . . . . . 862

44.4.2.4 A Graphical Course for the Workplace . . . . 862

44.4.2.5 The 2 hands.ch Website . . . . . . . . . . 864

44.4.2.6 Making the Knowledge Available

Where Needed . . . . . . . . . . . . . 864

References . . . . . . . . . . . . 864

44.4.3 The Danish Experience: Prevention of Skin Problems in Wet Work Employees . . . . . . 864 Elisabeth Held, Tove Agner

44.4.3.1 Intervention Studies . . . . . . . . . . . . . 864

44.4.3.2 Student Auxiliary Nurses (I) . . . . . . . . . 865

44.4.3.3 Wet Work Employees (Nursing Homes) (II) . 865

44.4.3.4 Discussion . . . . . . . . . . . 866

44.4.3.5 Important Messages . . . . . . . . . . . . . . . . 867

References . . . . . . . . . . 867 


\subsection{Prevention of and Protection from Contact Dermatitis (with Special Reference to Occupational Dermatology)}

JEAN-MARIE LACHAPELLE

\subsubsection{Introduction: General Principles and Considerations}

Preventive dermatology, which is claimed to play a key role in the global management of skin diseases, is not yet accepted as a routine procedure in many aspects of daily life [1]. The prevention of irritant and/or allergic contact dermatitis is briefly and incompletely reviewed in several textbooks on occupational and contact dermatitis $[2,3]$. It is therefore imperative to view the prevention of occupational (and nonoccupational) dermatitis as the cornerstone and/ or the final aim of many research projects in the field [4].

Various considerations must be borne in mind, particularly in occupational dermatology:

Contact dermatitis entails both individual aspects (some workers suffer many interruptions to their normal activities over the course of a year due to contact dermatitis) and socioeconomic aspects.

- The subject of prevention is usually divided into two sections: collective (or general) and individual protection measures [2]. There is a general principle: collective prevention and protection measures are usually more effective than individual measures, since the latter depend upon the personal will and constant application of each individual worker. Supervision and surveillance are crucial in this matter.

- The development of occupational medicine has afforded a safer working environment in most industrialized countries than was common a few years ago. Occupational physicians are well aware of general issues such as avoidance (or reduction to an acceptable level) of toxic substances in the working environment, reduction of noise, vibration and/or stress. Nevertheless, they feel less confident when tackling skin problems and seek advice from a dermatologist trained in the management of such situations.
Some categories of workers are not submitted to regular medical control at work; they may develop dermatitis that is not then treated at an early stage. On the other hand, this situation may differ considerably from one country to another.

In this chapter, the problem of preventing contact dermatitis will be discussed in terms of primary, secondary, and tertiary prevention. This approach permits a better evaluation of the situations encountered in daily life; it is particularly important for preventing and/or controlling outbreaks of irritant and/or allergic contact dermatitis that occur in various circumstances, covered by the areas of topical treatment of skin disease, dermatocosmetology and occupational dermatology.

In the next section we focus on the primary, secondary and tertiary prevention of allergic contact dermatitis. This concept can obviously be adapted for preventing irritant contact dermatitis as well as nonimmunological or immunological contact urticaria.

\section{Core Message}

A general principle: collective measures of prevention and protection are often more efficacious than individual measures, but they are not always applicable.

\subsubsection{Primary, Secondary, and Tertiary Prevention of Allergic Contact Dermatitis}

Prevention of allergic contact dermatitis can be divided into primary, secondary, and tertiary prevention. It is surprising that this concept and the terms themselves are absent in textbooks of occupational dermatology $[2,3,5]$, in view of the fact that the concept is commonly encountered in occupational medicine and public health surveys.

Primary prevention of allergic contact dermatitis focuses on the induction of contact sensitization and on controlling the exposure that eventually leads to contact sensitization. In other words, it includes all measures (collective and/or individual) that are taken before any sign of contact sensitization is observed amongst workers or consumers. These meas- 
ures are related to the knowledge of a potential risk in the environment.

Secondary prevention is applied when the first clinical signs of allergic contact dermatitis have occurred in a limited number of individuals. This stage of action focuses on a well-defined signal: the early manifestation of the elicitation phase of contact dermatitis.

Tertiary prevention relates to all of the measures used when the condition has developed and is becoming a clear-cut reality and a distressing impairment to the quality of life. This type of prevention is more difficult to manage; indeed, it has to be applied in a suspicious atmosphere, particularly in the field of occupational medicine.

The measures taken for primary and secondary prevention can differ in some respects, but in some cases the exposure assessment performed for secondary prevention can provide the knowledge required to perform primary prevention. Similarly, the measures taken for primary prevention may constitute

Table 1.1. Primary prevention of allergic contact dermatitis

\footnotetext{
Use of potent haptens in closed systems

Replacement of strongly haptenic chemicals by chemicals of weak or null haptenic potential

Reduction of hapten content in industrial products (such as addition of iron sulfate to cement to reduce the amount
} of free chromate salts)

Hapten (or allergen) removal, for example in topical drugs and/or cosmetic formulations (monitoring of drugs and cosmetics); checking for hypoallergenicity is a constant aspect of daily life

Specific measures in the work environment, such as automation, ventilation, medicotechnical supervision, and encapsulation of allergic chemicals

Measurements of atmospheric pollution in order to monitor and ultimately reduce the amount of aeroallergens

Initiatives to increase general knowledge of the chemical compositions of end-products

Protective clothing (with special attention to gloves)

Use of "barrier" creams and/or gels before and during work (not very effective compared to preventing irritant contact dermatitis)

Systematic use of moisturizing creams after work, in order to restore the skin barrier function

Labeling of cosmetics, end-products in industry, and so on

Medical education of consumers and workers by means of posters, teaching sessions for people at risk, courses on prevention of skin disorders and skin protection; this has gained more attention in the past few years and is highly recommended

Medical guidelines related to vocational choice (mainly for atopics) secondary prevention by preventing new outbreaks in sensitized subjects [6]. The procedures used to eradicate allergic contact dermatitis in preventive dermatology are presented in Tables 1.1-1.3.

Table 1.2. Secondary prevention of allergic contact dermatitis

Early detection of the incipient clinical signs of allergic contact dermatitis

Careful investigation of anamnestic data, leading to a probable direct link between environmental conditions and clinical signs

Establishment of diagnostic procedures in order to assess the aetiological factors (patch tests, repeated patch tests when needed, prick tests, open tests, semi-open tests, repeated open application tests, use tests, and so on)

In the case of positive allergic reactions, determination of their relevance

Information systems: product labeling, leaflets on product types or occupations, databases

Protective clothing (with special attention to gloves)

Use of appropriate "barrier" creams and/or gels, with awareness of all the limitations linked to the insufficient protective effects of such products

Skin cleansers of low irritant potential

Discussion and conclusions leading to the removal or the reduction of contact with the offending agent(s)

Table 1.3. Tertiary prevention of allergic contact dermatitis

Diagnosis of disabling allergic contact dermatitis

Careful investigation of anamnestic data, leading to a probable direct link between environmental conditions and clinical signs

Establishment of diagnostic procedures in order to confirm the aetiological factors (patch tests, repeated patch tests when needed, prick tests, semi-open tests, open tests, repeated open application tests, use tests, and so on)

Determination of the relevance of positive reactions, using as many approaches as possible

Removal of the allergen(s)

Development of an individual strategy based on reduction of contact, wearing protective clothes

Treatment of allergic contact dermatitis (topical and/or systemic)

In occupational dermatology, registration of the side effects and application of legal measures

(which may differ from one country to another)

Alleviation of potential conflicts in the industrial environment

Psychosocial approach to solving the problem 


\section{Core Message}

Strategies used to prevent allergic contact dermatitis can be classified into primary, secondary, and tertiary. Primary prevention is the ultimate goal to reach for all responsible persons: dermato-allergologists, occupational physicians, safety officers, and companies.

\subsubsection{Allergies to Dental Acrylates: A Specific Example to Illustrate a Program of Prevention}

Occupational allergic contact dermatitis arises in dental surgeons from the use of acrylic resins in composite materials. This provides an example that we can use to illustrate the preventive program. In this type of allergic reaction, fingertip dermatitis is the most common clinical symptom, but as exposure continues, the sides and the backs of the fingers also become involved [7]. The most commonly used acrylates are ethylene glycol dimethacrylate (EGDMA), diethyleneglycol dimethacrylate (DEGDMA), and trimethylpropane trimethacrylate (TMPTMA). Most of the dental composite resin materials are "diluted" with less viscous "difunctional" acrylates. These are the methacrylic monomers, of which EGDMA, DEGDMA, triethyleneglycol dimethacrylate (TREGDMA) and 1,4-butanedioldimethacrylate (BUDMA) are the most extensively used.

To further primary prevention [8], dental products containing acrylics should be delivered in bottles or packaging that allow no-touch techniques to be used for handling. This is currently not the case, and another approach is needed: to educate dentists about the risks that can result from touching dental composite resins and dentin primers without wearing gloves.

Secondary prevention is related exclusively to the use of appropriate gloves. Rubber gloves are readily penetrated by acrylics [9]. Polyvinylchloride, polyethylene, polyvinylacetate and polyvinylalcohol plastic gloves are also inadequate. A new glove material has been introduced, the 4 - $\mathrm{H}$ glove (Safety 4 AS, Lyngby, Denmark), a laminate made of five layers of polyethylene-ethylenevinylalcohol copolymer polyethylene (PE/EVOH/PE) - with a thickness of $0.065 \mathrm{~mm}$, and this has been shown to inhibit the penetration of various acrylates [10]. Nevertheless, the 4-H glove does not have a sufficiently close anatomical fit for delicate tasks. It has therefore been suggested that a fingerpiece from the $4-\mathrm{H}$ glove may be used under a disposable glove by dental personnel. Another possibility is to use the fingerpiece outside the disposable latex or vinyl glove [11]. In practice, when manipulations are of short duration, the use of a nitrile glove (N-Dex Best glove; Best Manufacturing, Menlo, Ga., USA) is quite convenient, despite the fact that such a glove can theoretically be penetrated by acrylics.

In the example under consideration, tertiary prevention is very similar to secondary prevention. In some rare instances, fingertip dermatitis does not heal completely and requires long-term topical therapy, including corticosteroid and emollient preparations.

\subsubsection{Primary, Secondary, and Tertiary Prevention of Irritant Contact Dermatitis}

The major task is to establish a precise diagnosis of irritant contact dermatitis. This implies that allergic contact dermatitis has been ruled out, based on a careful investigation including some of the various procedures mentioned in Tables 1.1-1.3. When an accurate diagnosis of irritant contact dermatitis has been reached, measures of primary, secondary and tertiary prevention are clearly delineated. In many respects, they are comparable to those applied in allergic contact dermatitis.

Two points deserve special attention:

- Removal of the irritant(s) is usually optional. Measures leading to the reduction of the offending contacts in terms of frequency, concentration, and so on are usually sufficient. For example, reducing the daily number of shampoos by young hairdressers prevents severe irritant contact dermatitis. Another example concerns the use of biocides that are sometimes added "wildly" to cutting oils in certain plants.

- The use of "barrier" creams and/or gels before and during work is more effective against irritation than against allergy (see later). This is also true for protective clothing, particularly gloves.

There is still a high prevalence of irritant contact dermatitis in various sectors of activity. Therefore, the 
current experience puts an emphasis on its careful prevention, particularly in terms of worker's education and teaching programs.

\section{Core Message}

Measures taken for primary, secondary and tertiary prevention of irritant contact dermatitis are one of the most important challenges in environmental dermatology.

\subsubsection{An Overview of Applicable Collective Measures of Prevention and Protection}

Various procedures can be used to achieve an efficient program of prevention and/or protection. The strategy of prevention is not limited to occupational life, but extends to all activities of daily life that imply contacts with either irritants or allergens. The various measures are intended to reduce contact with irritants and/or allergens.

\subsubsection{Use of Potent Allergens in Closed Systems}

It is absolutely essential that very potent allergens are kept in "closed systems"; any contact with intact or damaged skin of workers must be avoided. For instance, 2,4-dinitro-1-chlorobenzene (DNCB) has been used extensively as an algicide in air-conditioning cooling systems [12]. It is clearly kept in a closed system; nevertheless, maintenance or repair activities involve "insidious" occasional contact between some categories of workers and the allergen. This can provoke epidemics of contact dermatitis involving such workers. A similar situation can occur with various plasticizers and other additives in synthetic polymers [13].

\subsubsection{Automation}

Automation is the only practical means of avoiding some epidemics of contact dermatitis in industry. There are many examples of industrial airborne irritant contact dermatitis that could not be resolved by individual measures of protection. Automation of the industrial procedure has been advised in several such cases. This is especially true when dust particles are responsible for skin irritation [14]. An epidemic of slag dermatitis was reported [15] in a metallurgic plant where permanent mold casting techniques had been introduced. At one stage of production, workers poured slag (a mixture of silicium oxide and calcium oxide powders) into ingot molds. Dust, penetrating through protective clothes or between sleeves and gloves, accumulated in the flexures and on the extensor aspects of the thighs and arms. Subjective and objective skin symptoms were similar to those of fiberglass dermatitis. Scratch marks, papules and pustules were sometimes present. Microscopic examination of powder particles revealed that some were oblong and sharp-edged (length: $\pm 10-80 \mu \mathrm{m}$ ). The dermatitis was considered to have arisen due to mechanical irritation of the skin by sharp-edged particles. We reviewed the problem and dispersed several samples of different slag particles in distilled water. The $\mathrm{pH}$ of the supernatant measured between 8 and 12 . Slag dermatitis was therefore caused not only by the roughness of the particles, but also was also due to irritation by alkali. This large-scale occupational problem demanded effective measures and has been solved by complete automation.

Among photographers, the problem of allergic contact dermatitis from color developers has been solved almost completely in Scandinavian countries with the widespread use of automated procedures $[16,17]$. Nevertheless, some cases are still observed among technicians who use "artistic" (nonautomated) procedures. The drawback of automation is also related to maintenance and repair, during which workers may be caught off-guard.

The recent switch from cameras based on photographic film to digital cameras provides a good illustration of the continuously changing nature of occupational dermatology. This example, a significant problem discussed in former editions of the book, is insignificant these days.

\subsubsection{Allergen Replacement or Removal}

Allergen replacement (or removal) is a possible solution to many problems from allergic contact dermatitis. Some of the following examples are difficult to apply, whereas others are simple:

Replacement of epoxy resins by other types of resins [13]. Theoretical; not easy in practice.

- Use of epoxy resins with a molecular weight greater than $1 \mathrm{kDa}$ [18]. Theoretical; not easy in practice. 
Substitution of a catalyst or curing agent in an epoxy resin system [13]. Can be discussed and realized in practice.

- Replacement of accelerators and antioxidants in rubber factories. Conceivable in practice.

- Addition of ferrous sulfate to cement. Cement causes dermatitis not only in areas directly exposed to the dust but also in areas covered with dust-impregnated clothing. Premixed cement delivered wet to the workplace eliminates the dust hazard to some extent. The addition of ferrous sulfate to cement immediately before mixing reduces the hexavalent chromium to the trivalent state and may thus prevent dermatitis. In some countries, ferrous sulfate is available in sacks to be added to cement (Melstar, marketed in the Netherlands). Its use is not always possible in practice for various reasons. Follow-up of workers, in order to evaluate the efficacy of such a preventive measure, has shown the value of adding ferrous sulfate, but it is nonetheless difficult to evaluate its precise impact, since automation has also played an important role in reducing the number of affected workers [19].

- Removal of chromate from household and/or industrial products is essential. Calnan has emphasized that "chromate sensitization produces such a chronic and recalcitrant dermatitis that dermatologists should always try to limit its use in materials or fluids, which may contaminate the skin, even in low concentrations" [20]. The presence of sodium dichromate in eau de Javel is no longer justified, either as a coloring agent or a stabilizer. The decision to remove sodium dichromate from eau de Javel by the French Trade Society of producers in Paris was a notable example of such an effort in preventive dermatology. In this case, one of the arguments in favor of removal was the fear raised by the medical authorities of provoking and/or perpetuating allergic contact dermatitis from chromate among users. It is interesting to note that this measure is not only important for preventing housewives' dermatitis but also for occupational dermatology, since eau de Javel is used on a large scale for cleaning or antiseptic purposes [21].

- Replacement of a biocide as an additive in many industrial products such as soluble oils. This is a fairly common problem, relatively easy to solve in practice.
The removal of irritants or allergens can also be achieved, at least in part, with general local exhaust ventilation.

In the field of dermatocosmetology, the example of Kathon CG is rewarding in many respects. The biocide $\mathrm{Cl}+\mathrm{Me}$-isothiazolinone (Kathon CG; Rohm and Haas, Philadelphia, Pa., USA) provoked outbreaks of allergic contact dermatitis among consumers of cosmetic products in the 1980 os and early 1990s. Most of the cases occurred when Kathon CG was incorporated into "leave-on" formulations, at a concentration of $15 \mathrm{ppm}$. Removal of the biocide was necessary due to many complaints from consumers and dermatologists. It was decided to maintain Kathon CG as a biocide in "rinse-off" formulations, such as in shampoos, at a concentration of $7.5 \mathrm{ppm}$. Such shampoos are well tolerated by patients who had previously experienced allergic problems with "leaveon" preparations containing Kathon CG at 15 ppm. In this example, the risk analysis process for a microbiocide with broad applications as well as varied human exposure patterns involves assiduous planning, along with development and implementation of appropriate actions to monitor and reduce risk levels [22].

\subsubsection{Measures Promoting the Proper Use of Industrial Irritants or Allergens}

One very important measure to be applied in factories is the proper use of many chemicals. It is noteworthy that some products are not used as advised by the manufacturer. Two examples serve to illustrate this situation.

Biocides are very often used at excessively high concentrations in industrial fluids. Workers attempt to "rejuvenate" solutions by reducing bacterial contamination with unacceptable amounts of biocides. Increased concentrations of biocides can be responsible for outbreaks of irritant or allergic contact dermatitis.

Glutaraldehyde solutions are used to disinfect rooms in hospitals. Cases of allergic contact dermatitis can be observed among staff members when glutaraldehyde solutions are sprayed, for instance, over radiators, the vapors being responsible for airborne contact dermatitis. 


\subsubsection{Visit of the Dermatologist to the Workplace}

Occasionally, when a difficult dermatological issue arises in a factory, a more in-depth investigation of the (presumable) occupational dermatosis requires a factory visit [5].

Indeed, the worker's conditions cannot be fully appreciated in the office by the dermatologist, even when he (or she) is well acquainted with occupational problems [3]. A visit to the workplace makes it easier to gain insight into the work environment.

Questions related to the workplace would probably include [3]:

The nature of each chemical used (with its complete formulation)

- All steps and/or procedures involved in the manufacturing process

- Occupational positions at different stages of work

The protective and cleaning measures used by the workers (see later)

- The psychological "atmosphere" at the workplace and, more generally, in the factory

Independently from the visit to the workplace, the organization of a joint meeting in the factory may play a useful role. All plant representatives should ideally be present: manager, industrial hygienist (safety officer), occupational physician, occupational nurse (if any!), and trade unions representatives.

Following the visit, the skin investigation of the worker should be performed at the clinic or the private office, where the worker is "reconsidered to be a patient". Testing at the factory is a last resort that is not usually advisable.

\section{Core Message}

Visiting factories or other work facilities is very rewarding; it can provide useful information on many aspects of occupational life.

\section{References}

1. San Marco JL (1997) Prevention. In: Grob JJ, Stern RS, Mac Kie RM, Weinstock WA (eds) Epidemiology, causes and prevention of skin diseases. Blackwell Science, Oxford, pp $16-26$

2. Lachapelle JM, Frimat P, Tennstedt D, Ducombs G (1992) Précis de dermatologie professionnelle et de l'environnement. Masson, Paris, pp 273-288

3. Marks JG Jr, Elsner P, de Leo V (2002) Contact and occupational dermatology, 3nd edn. Mosby, St Louis, Mo., pp 323-338

4. Lachapelle JM (1997) Prevention of allergic contact dermatitis. In: Grob JJ, Stern RS, Mac Kie RM, Weinstock WA (eds) Epidemiology, causes and prevention of skin diseases. Blackwell Science, Oxford, pp 318-323

5. Funke U (2000) Risk management of occupational hazards at the workplace. In: Kanerva L, Elsner P, Wahlberg JE, Maibach HI (eds) Handbook of occupational dermatology. Springer, Berlin Heidelberg New York, Ch 45, pp 367-370

6. Lachapelle JM (1999) Preventive measures in allergic contact dermatitis. In: Dyall-Smith D, Marks R (eds) Dermatology at the millennium. Parthenon, New York, pp 234-238

7. Kanerva L, Henriks-Eckerman ML, Estlander T (1994) Occupational allergic contact dermatitis and composition of acrylates in dentin bounding systems. J Eur Acad Dermatol 3:157-168

8. Kanerva L, Estlander T, Jolanki R, Tarvainen K (1995) Statistics on allergic patch test reactions caused by methacrylate. Am J Contact Dermat 6:1-4

9. Pegum JS, Medhurst FA (1971) Contact dermatitis by acrylic monomer. Br Med J 2:141

10. Roed-Petersen J (1989) A new glove material protective against epoxy and acrylate monomer. In: Frosch P, Dooms-Goossens A, Lachapelle JM, Rycroft RJG (eds) Current topics in contact dermatitis. Springer, Berlin Heidelberg New York, pp 603-606

11. Kanerva L, Turjanmaa K, Estlander T, Jolanki R (1991) Occupational allergic contact dermatitis from 2-hydroxyethyl methacrylate (2-HEMA) in a new dentin adhesive. Am J Contact Dermat 2:24-30

12. Malten KE (1974) DNCB in cooling water. Contact Dermatitis Newsletter 15:466

13. Björkner B (2000) Plasticizers and other additives in synthetic polymers. In: Kanerva L, Elsner P, Wahlberg JE, Maibach HI (eds) Handbook of occupational dermatology, chap 85. Springer, Berlin Heidelberg New York, pp 688-690

14. Lachapelle JM (1987) Industrial airborne irritant contact dermatitis due to dust particles. Boll Dermatol Allerg Prof 2:83-89

15. Lachapelle JM (1984) Occupational airborne irritant contact dermatitis to slag. Contact Dermatitis 10:315-316

16. Lidén C, Brehmer-Andersson E (1988) Occupational dermatoses from colour developing agents. Clinical and histopathological observations. Acta Derm Venereol (Stockh) 68:514-522

17. Lidén C, Sollenberg J, Hansen L, Arvidson A (1989) Contact allergy to colour developing agents. Analysis of test preparations, bulk chemicals and tank solutions by highperformance liquid chromatography. Derm Beruf Umwelt $37: 47-52$

18. Thorgeirsson A, Fregert S, Fammas O (1978) Sensitization capacity of epoxy resin oligomers in the guinea pig. Acta Derm Venereol (Stockh) 58:17-21 
19. Avnstrop C (1989) Follow-up of workers from the prefabricated concrete industry after the addition of ferrous sulphate to Danish cement. Contact Dermatitis 20:365-371

20. Calnan CD (1978) Chromate in colorant water of gramophone record presses. Contact Dermatitis 4:246-247

21. Lachapelle JM, Lauwerys R, Tennstedt D, Andanson J, Benezra C, Chabeau G, Ducombs G, Foussereau J, Lacroix M, Martin P (1980) Eau de Javel and prevention of chromate allergy in France. Contact Dermatitis 6:107-110

22. Frosch PJ, Lahti A, Hannuksela M et al (1995) Chloromethylisothiazolinone/methylisothiazolinone (CMI/MI) use test with a shampoo on patch-test-positive subjects: results of a multicenter double-blind crossover trial. Contact Dermatitis $32: 210-217$

\subsection{Skin Protection and Skin Care}

\section{W. Wigger-AlberT I}

\subsubsection{Introduction}

Contact dermatitis, particularly that of the hands, remains the most prevalent occupational skin disease in the industrialized world, resulting in individual morbidity and impacting economically on the community. Since the course may be chronic, leading to disability, and since treatment is frequently of limited efficacy, prevention should be emphasized in order to reduce the incidence and prevalence of both irritant contact dermatitis (ICD) and allergic contact dermatitis (ACD). The incidence of ICD therefore closely correlates with exposure to skin-damaging materials and to wet work conditions [69]. Apart from total elimination of cutaneous contact with hazardous substances and the use of gloves or protective clothing, protective creams/gels (PC), or so-called "barrier creams," are one of the classical means of protecting skin on the hands against low-grade hazards from the environment.

The search for protective creams started in 1915, when a general practitioner from Wigan, England, Dr R. Prosser White, wrote that it was necessary that men's clothes and skin should be protected by overalls and suitable covering. Any cutaneous surfaces that were soiled were to be cleansed as soon as possible. To assist in this, it was advised that a bland, insoluble ointment was to be rubbed into the exposed surfaces prior to work. The quantity used was not to be large, but enough to block up the stomata of the skin [13]. In general, this concept is still true for the use of PCs at the workplace. However, we must bear in mind that skin protection products cannot offer the same level of protection as gloves. Preparations marketed as being an "invisible glove" may encourage workers at risk to be careless upon contact with irritants. On the other hand, they often remain the
Table 2.1. Dermatological skin protection in the workplace

\begin{tabular}{|c|c|c|}
\hline $\begin{array}{l}\text { Type of } \\
\text { product }\end{array}$ & $\begin{array}{l}\text { Time of } \\
\text { application }\end{array}$ & Formulations \\
\hline $\begin{array}{l}\text { Pre-exposure } \\
\text { protective } \\
\text { creams }\end{array}$ & $\begin{array}{l}\text { Before and } \\
\text { during } \\
\text { work }\end{array}$ & $\begin{array}{l}\text { o/w emulsions, w/o emul- } \\
\text { sions, multiple w/o/w } \\
\text { emulsions, tanning agents, } \\
\text { aluminum chlorohydrate, } \\
\text { zinc oxide, talcum, perflu- } \\
\text { orpolyethers, chelating } \\
\text { agents, quarternium-18 } \\
\text { bentonite, UV absorbers }\end{array}$ \\
\hline $\begin{array}{l}\text { Cleansing } \\
\text { products }\end{array}$ & $\begin{array}{l}\text { During and } \\
\text { after work }\end{array}$ & $\begin{array}{l}\text { Detergents, solvents, natu- } \\
\text { ral and synthetic grits }\end{array}$ \\
\hline $\begin{array}{l}\text { Post- } \\
\text { exposure } \\
\text { skin care }\end{array}$ & $\begin{array}{l}\text { Mainly after } \\
\text { work }\end{array}$ & $\begin{array}{l}\text { Emollients, moisturizers, } \\
\text { humactants (including } \\
\text { glycerol, sorbitol, urea), } \\
\text { lipids }\end{array}$ \\
\hline
\end{tabular}

only practical preventative measure that can be used in occupations that require a good sense of touch, finger mobility, or when working at rotating machines.

Basically, the dermatological principle behind the use of an integrative skin protection in the workplace consists of pre-exposure PCs designed to prevent skin damage due to irritant contact, mild skin cleansers that remove aggressive substances from the skin, and post-exposure skin care products such as emollients or moisturizers that restore the natural barrier function and increase skin hydration and skin smoothing (Table 2.1) $[42,78]$. It is debatable as to whether a strict distinction between skin care products used before and after work is justified, since emollients alone have been shown to treat and prevent ICD [63]. Moreover, the benefit of an integrated skin protection based on different products has only rarely been validated [7]. However, it should be kept in mind that a strict and easily understandable separation into pre-exposure PCs, mild skin cleansers and post-exposure skin care products might be necessary to increase the acceptance and appreciation of skin care at the workplace. Most manufacturers offer special plans to pursue this aim. This chapter reviews essential work on the benefits of pre-exposure PCs.

\section{Core Message}

Protective creams are not intended to replace other personal protection measures. They are recommended in conjunction with technical measures and upon the use substances that are less irritating to the skin. 


\subsubsection{Protection Principles}

During recent years the prevailing opinion on PCs has been that they are effective in a purely physical way, since their composition enables a diffusion barrier against the offending irritant to be built up to prevent penetration. Hazardous substances with similar physico-chemical properties are grouped together (for example water-miscible or non-watermiscible) to simplify the process of choosing a product $[13,42]$. In agreement with this common principle, water-in-oil (W/O) emulsions should provide benefit against hydrophilic and water-soluble irritants such as detergents, acids, alkalis, metal working fluids, and even plain water. Oil-in-water $(\mathrm{O} / \mathrm{W})$ emulsions are recommended against hydrophobic irritants such as oils, varnishes and organic solvents. However, the theory that the product builds up a physical barrier between the skin and the irritant, and that the formulation remains unchanged after the product has been applied to the skin, may be incorrect [21]. Additionally, in many workplaces skin contact with both water-miscible and non-watermiscible irritants is unavoidable, and a simple formulation may not prevent against both types of irritants. Moreover, it must be pointed out that the efficacy of a skin protection product cannot be judged theoretically on the basis of the formulation concept alone; it has to be examined individually in sufficient test models.

Special investigations have been undertaken to develop preparations with dual modes of action, combining the different effect of hydrophilic ingredients such as propylene glycol, glycerol and sorbitol with those of lipophilic ingredients such as stearic acid and dimethylpolysilicane. However, a foamy skin protector ("invisible glove") that was claimed to form a two-dimensional network of crystalline stearic acid that was impermeable to hydrophilic agents failed a repetitive irritation test involving the anionic detergent sodium lauryl sulfate (SLS) and the solvent toluene (TOL) [20]. Other preparations are supposed to build up a firm second layer on the skin, which prevents penetration of various agents in a steric manner, including a fatty amine amide acetate that binds to negatively charged carboxyl groups of keratin, and a positive fatty ammonium ion that binds firmly to the negative charge of the epidermis [21].

Some products are claimed to have special protective properties due to tanning agents that are used to generate a hardening effect on the skin surface, increasing the resistance of the skin to mechanical hazards or irritants. Tanning agents are also contained in PCs recommended for use under occlusive gloves to reduce skin maceration due to occlusion $[1,37,94,95]$.
The decreased swelling is caused by direct binding of the tanning substance to keratin. Aluminum chlorohydrate in combination with glycerol was experimentally demonstrated to be more effective at countering skin irritation than glycerol alone [28], and was additionally found to reduce the increased sweating of the hands induced by wearing gloves [9].

Perfluorpolyethers are chemically unreactive liquid polymers with special physico-chemical properties that have recently shown promise as protective preparations in the prevention of ICD $[17,66]$. Zinc oxide has a shielding effect. Some products include additional ingredients to counter artificial and natural UV light. Chelating agents, or other substances that can bind metal ions or reduce the penetration through the skin have also been intensively investigated [65]. Although the model formulations were shown to have some benefit in sensitized individuals under experimental conditions $[8,70]$, their use in the prevention of $\mathrm{ACD}$ has been disappointing under practical conditions. However, some publications indicate a benefit from some PCs used as "active" creams to prevent $\mathrm{ACD}$, from using complexing agents against nickel allergy, or from using quaternium-18 bentonite against poison ivy/oak ACD [23, 25, $31,34,53,56,64,89]$. Recently, a new approach with natural vegetable fats has been presented to investigate their abilities to suppress ICD in the foodstuffs industry, due to their special requirements and problems regarding the taste and smell of products [67].

\section{Core Message}

The complex interaction between a cream formulation and the specific irritant must be examined individually in sufficient test models.

\subsubsection{Proof of Efficacy}

Much effort has been undertaken to develop valid methods for evaluating the actual protective properties of PCs. Of course, intervention studies in factories are required for proper assessment, but doubleblinded, placebo-controlled, randomized clinical tests of PCs are still missing due to methodological difficulties, ethical doubts, and the enormous expenditure directed towards the tests in relation to the preventative benefit of PCs in practice. Publications on real intervention studies of PCs in a workplace setting are scarce $[6,22,30,58]$. In most studies the 
interpretation is difficult due to the small sample size, or because of the short follow-up. The observed effect is a combination of the intervention effect being measured, and a number of disturbing variables reflecting the organizational complexity of such studies [12]. Therefore, the potential effect of PCs in the prevention of work-related hand eczema has mostly been documented in a laboratory setting and on experimentally damaged skin. The majority of information available is based on these experiments.

Since Suskind introduced the "slide test" to evaluate PCs in the 1950s [71], various in vitro studies using penetration, diffusion and absorption models along with excised human skin or reconstructed epidermis have been performed to investigate both the effects of irritants on skin barrier function and the benefit of PCs under highly experimental conditions $[10,14,15,18,26,27,32,33,41,47,51,52,54,62,72-75,77$, $90,92,96]$. However, all of these studies are not considered close enough to real workplace situations. Promising results from investigations using the isolated perfused bovine udder skin model have been presented recently and compared to human in vivo data [40, 61]. Patterson et al [57] evaluated the ability of a commercially available PC to reduce irritation against SLS in a repeated patch test, while Fowler [17] demonstrated improvement of hand dermatitis after using the cream for six weeks in a non-placebo-controlled study.

In 1994, Frosch and Kurte introduced the repetitive irritation test (RIT), with cumulative irritation over a two-week period by standard irritants such as SLS, sodium hydroxide, lactic acid and TOL [21]. A specific profile of PC efficacy could be demonstrated by quantifying irritant cutaneous reactions by noninvasive measurements. In recent years, this model has been used in many laboratories as a routine procedure, as it is considered to be suitable for comparing results from the use of PCs simultaneously with a non-pretreated control site on the volunteers' back. However, manufacturers of skincare products prefer easy study protocols that provide valid data in a short time with few restrictions on the volunteers. Therefore, the short duration and easy application associated with a one-week test using the forearms of healthy volunteers was highly desirable.

In a next step, a repetitive irritation test on based on the RIT was developed to optimize the concentration of irritants against which PCs are tested and to evaluate the necessary cumulative application time $[83,84]$. Using a set of various irritants modified in terms of their different concentrations and their application to volunteers' ventral forearms, it could be demonstrated that a one-week period was sufficient to evaluate the efficacy of PCs against most irritants, even if lower concentrations of irritants were used. Based on the RIT, a national multi-center study was subsequently designed to standardize a test procedure for the evaluation of skin protective products. A repeated short-time occlusive irritation test (ROIT) was evaluated in two parts ( 12 day and 5 day protocols) in four and six skilled centers, respectively. Using two irritants (SLS and TOL, each applied twice daily for $30 \mathrm{~min}$ twice a day for $30 \mathrm{~min}$ ) and three different cream bases with different hydrophilicities, the evaluation showed that significant results could be readily achieved with the 5-day protocol. Furthermore, the ranking of the vehicles regarding reduction of the irritant reaction was consistent in all centers [68].

Despite promising data, one criticism is that in all models presented, the investigation of PC efficacy has been limited to exposure to only a single irritant. Skin exposure in the occupational setting can be very complex. Hydrophilic and hydrophobic irritants such as the anionic surfactant SLS and the organic solvent TOL have mainly been used in studies, but repetitive contact to both hydrophilic and hydrophobic substances together or, more commonly, one after the other, occurs regularly in the workplace setting. For instance, workers in the metalworking industry are repeatedly exposed to water-based metal working fluids, neat oils, detergents and organic solvents. Therefore, interactions between irritant chemicals have significant practical consequences. Indeed, concurrent application of SLS and TOL was shown to induce significantly stronger reactions than those caused by twice daily application of each irritant on its own [85]. This additive effect of mixed irritant application impacts upon the use of PCs in practice and upon the way that PCs should be tested. In a recent study, the benefit from a commercially-available PC compared to non-pretreated control sites was tested against the sequential application of two irritants in the so-called tandem repeated irritation test (TRIT). A significant protective effect from the PC was obtained against treatment combinations SLS/SLS and SLS/TOL [87]. Interaction of further irritants should be investigated with attention to professions where a multitude of hazardous substances may cause ICD.

We should note here that some authors found that the PC gave no protection, or even aggravated ICD. A foamy "skin protector" was not convincing in a guinea pig model, and it also caused an aggravating effect on the existing irritation due to $\mathrm{NaOH}$ [20]. Also using a guinea pig model, it was shown that treatment with PC can increase skin irritated by cutting oil fluids [29]. Boman and Mellström showed that the absorption of butanol through stripped skin treated with PC was higher than the absorption through un- 
treated skin [11]. A PC was shown to amplify the inflammation from TOL [83], and its protective properties against the systemic absorption of solvents were less than adequate $[10,41,46]$.

Besides not being very effective against irritants or even amplifying barrier damage, the creams themselves may induce ICD or ACD $[35,60]$. Preservatives, cream bases such as wool alcohols, emulsifiers and fragrances have an irritant and allergic potential of their own, and should be chosen with care.

\section{Core Message}

Relevant irritants must be included in standardized test designs. In vitro methods may help to discriminate between different formulations. Repetitive irritation tests in humans are more closely related to actual situation in the workplace.

\subsubsection{Usage and Application}

The cosmetic acceptance of PCs must be sufficient, because their use is often avoided in cases where a tight grip of tools and small objects is necessary. Additionally, PCs are not intended for use on diseased skin; only on mainly intact skin. They should be applied before contact with irritants, and reapplied after every break or after a certain period of time (half a work shift according to manufacturers' claims). Before the product is reapplied, the skin must be cleaned and dried properly to avoid increased penetration of any remaining irritants on the skin surface [42].

It is clear that the effectiveness of a PC is also influenced by the application itself. They must be applied not only frequently enough but also in adequate amounts and to all skin areas that need protection. In particular, the PC should be applied properly into the interdigital spaces. Studies with a fluorescentmarked PC have indicated that the application of PC was the worst for different professional groups and patients with hand eczema, especially in the dorsum of the hands and the interdigital spaces, excluding the space between the index finger and the thumb [79-81]. This method is now covered by many worker education programs and programs to evaluate product application and acceptance [3,5]. A simple device with a fluorescent source (a Dermalux checkbox) can be used as a training tool in critical occupational working conditions to visualize and teach the proper use of a PC, giving direct feedback about the most commonly unprotected regions [39]. This experience, rather than anonymous instructive brochures given to the workers, can initiate changes in behavior $[48,81]$.

\section{Core Message}

Even the best product is of little, if any, benefit when insufficiently applied.

\subsubsection{Strategies}

Though PCs are one of the common measures employed to prevent ICD, their actual benefit in the workplace remains controversial $[36,44]$ and is debated in recent reviews $[2,45,50,82,86,93]$. It has recently been suggested that, in analogy to the sun protection factor, a standardized testing method could be used to specify (irritant-specific) "skin protection factors" for each PC. Reasons for a lack of protection in practice are obviously inefficient products [20], products that are effective against a special irritant but that aggravate reactions from to other irritants [83], or insufficient application of products on exposed skin areas [79]. Data from in vitro and in vivo tests underline the importance of careful selection of PCs for specific workplaces. Choosing the wrong preparation may well worsen the effect of an irritant.

PCs are still not perfect. Much effort is needed to develop products that will give more protection and fewer side-effects. Efficacy and cosmetic acceptance are both important qualities of skin care products that provide protection in the workplace, but knowledge of how they are correctly used is critical. It goes without saying that their ability to prevent ICD and ACD must be evaluated in reliable studies. Results from animal experiments may not be valid for humans, particularly when dealing with irritants, in view of their complex action mechanisms and the high inter-individual variability of the susceptibility of human skin [91]. Considering the various models used to investigate the efficacy of skin care products, the validation of a sensitive, standardized and widely accepted model proved by interlaboratory standardization or controlled clinical studies in the workplace still seems to be necessary. Clearly, studies performed both under experimental conditions and in the workplace are needed before a rational recommendation about whether a product is safe and effective for skin protection can be made. Up to now, it has been largely unclear whether the various in vitro and 
in vivo methods used are suitable for simulating real workplace conditions, and whether these test results can be related to real occupational exposure. Further studies, especially under daily working conditions evaluating the contribution of each single element of the skincare program (products, frequency of application and education programme) are needed to produce evidence-based recommendations for skin protection [44]. However, repetitive studies in humans even if they are experimental - are still the gold standard. Supplementary test methods can be used as screening tests but they must be compared to in vivo methods such as ROIT that are more closely linked to real life situations [40].

Due to the wide range of potential irritants at the workplace, standard irritants are often used to examine the effectiveness of products in relation to groups of irritants (for example detergents). This is permissible if the manufacturer states the fact that the examination was performed using a model. Whenever protection against an individual substance, groups of working materials or other substances hazardous to skin is claimed, it must be proven that the skin protection was examined against these substances. If the use of PCs is recommended against a combination of irritants, models with this combination of irritants should be used [87]. The same is true for the benefits from an integrative skin protection concept and the interactions of protection, skin cleansing and regeneration $[7,49]$.

The majority of investigation takes place in healthy volunteers exposed with standardized and relevant irritants. Additionally, prospective cohort studies and intervention studies $[4,16,24,38,76]$ or randomized and controlled studies with the inclusion of a placebo $[6,55,58]$ may contribute important knowledge when examining the relevance of the experimental data and evaluating the actual use of the skin protection product in a concrete situation. Both model investigations and cohort or intervention studies need proper statistical analysis and a sufficient number of volunteers in order to reach significant differences between intervention and control. Correct biometric methods should be applied [43]. Recommendations for evaluating the efficacies of PCs have recently been published [88].

\section{Core Message}

Product claims must be based on relevant test methods. Human in vivo studies are still the gold standard.
Besides the use of products with proven efficacy, periodical training and motivation of individuals at risk is of utmost importance, because the best preventative measures have no effect when they are used irregularly and insufficiently. Special emphasis needs to be placed on educating the individual during apprenticeship. It is easier to train a preclinical student nurse in the correct use of protective products than to attempt to change their behavior after several years of work [48]. Up-to-date, informal academic presentations should be used to educate young people in professional training schools $[59,81]$. In the end, general education and training of exposed workers in the use of PCs and preventative measures will have the most impact on the prevention of occupational contact dermatitis. With the words of Maria Montesori in mind, we ask people that say that education is too expensive: what is the cost of ignorance [81]?

\section{Core Message}

Education is the basis of all prevention.

\section{Suggested Reading}

1. Frosch PJ, Kurte A (1994) Efficacy of skin barrier creams (IV). The repetitive irritation test (RIT) with a set of four standard irritants. Contact Dermatitis 31:161-168

The first standardized test in humans with a set of four relevant irritants. In contrast to previously published procedures, the back (instead of the forearm) and a total of four irritants were used. Different formulations could be simultaneously compared to the control field, which received the irritant only, without pretreatment with PC. The irritants sodium lauryl sulfate, sodium hydroxide, lactic acid and undiluted toluene were applied occlusively for $30 \mathrm{~min}$, over 2 weeks. The PCs tested were applied $30 \mathrm{~min}$ before contact with the irritants. Irritant cutaneous reactions were quantified by four parameters: erythema score, transepidermal water loss, blood flow volume and stratum corneum hydration by measuring capacitance. The main conclusion was that the accepted notion that oil-in-water emulsions against lipophilic irritants, and water-in-oil emulsions are primarily effective against hydrophilic irritants needs to be re-evaluated.

These observations still hold true after many years. The interaction between the skin, the formulation and the irritant is complex and must be evaluated in humans. Most repetitive test designs used nowadays are based on the RIT.

2. Schnetz E, Diepgen TL, Elsner P, Frosch PJ, Klotz AJ, Kresken J, Kuss O, Merk H, Schwanitz HJ, Wigger-Alberti W, Fartasch M (2000) Multicentre study for the development of an in vivo model to evaluate the influence of topical formulations on irritation. Contact Dermatitis 42:336-343 
This was the first national multi-center study performed to establish a standardized test procedure for the evaluation of skin protective products. Based on the RIT, a repeated short-time occlusive irritation test (ROIT) was evaluated in six skilled centers. The skin reaction was induced by two irritants (sodium lauryl sulfate and toluene). The irritation was monitored by bioengineering means (transepidermal water loss measurement, colorimetry) and by clinical scoring. The evaluation showed that significant results could be achieved with a five-day protocol. Furthermore, despite the expected inter-center variations due to the heterogeneity of the individual thresholds of irritation, interpretation of clinical scores, and inter-instrumental variability, the ranking of the PCs in terms of reduction of the irritant reaction was consistent in all centers.

It was of the utmost importance that the reproducibility of this test was demonstrated. By using a set of different bioengineering methods, three standard formulations were ranked in terms of their ability to prevent skin irritation caused by sodium lauryl sulfate.

3. Wigger-Alberti W, Maraffio B, Wernli M, Elsner P (1997) Self-application of a protective cream: pitfalls of occupational skin protection. Arch Dermatol 133:861-864 One hundred and fifty healthy workers in several occupations were recruited for a questionnaire interview and for typical self-application of a PC. Precisely how the workers applied the PC at the workplace was monitored and quantified by a fluorescence technique. Many areas were skipped when viewed under Wood light. The PC was incompletely applied, especially on the dorsal aspects of the hands and in the interdigital spaces.

Despite promising experimental data demonstrating the efficacy of protective creams (PC), their practical value is still viewed with scepticism. However, lack of protection could simply be caused by uneven or spotty application of these products. Individuals should be made aware of the most commonly missed regions in order to ensure complete skin protection. This simple method is a useful way to assess self-application and should be included in worker education.

\section{References}

1. Allmers $H$ (2001) Wearing test with 2 different types of latex gloves with and without the use of skin protection cream. Contact Dermatitis 44:30-33

2. Alvarez MS, Brown LH, Brancaccio RR (2001) Are barrier creams actually effective? Curr Allergy Asthma Rep 1: 337-341

3. Bankova L, Lindenau S, Fuchs S, Tittelbach J, Fischer TW, Elsner P (2002) Influence of the galenic form of a skinprotective preparation on the application pattern assessed by a fluorescence method. Exog Dermatol 1:313-318

4. Bauer A, Kelterer D, Stadeler M, Schneider W, Kleesz P, Wollina U, Elsner P (2001) The prevention of occupational hand dermatitis in bakers, confectioners and employees in the catering trades: preliminary results of a skin protection program. Contact Dermatitis 44:85-88

5. Bauer A, Kelterer D, Bartsch R, Pearson J, Stadeler M, Kleesz P, Elsner P, Williams H (2002) Skin protection in bakers' apprentices. Contact Dermatitis 46:81-85

6. Berndt U, Wigger-Alberti W, Gabard B, Elsner P (2000) Efficacy of a barrier cream and its vehicle as protective measures against occupational irritant contact dermatitis. Contact Dermatitis $42: 77-80$
7. Berndt U, Gabard B, Schliemann-Willers S, Wigger-Alberti W, Zitterbart D, Elsner P (2002) Integrated skin protection from work place irritants: a new model for efficacy assessment. Exog Dermatol 1:45-48

8. Blanken R, Nater JP, Veenhoff E (1987) Protective effect of barrier creams and spray coatings against epoxy resins. Contact Dermatitis 16:79-83

9. Bock M, Wulfhorst B, Gabard B, Schwanitz HJ (2001) Okklusionseffekt von Schutzhandschuhen/Effizienz einer Aluminiumchlorhydrat-haltigen Hautschutzcreme. Derm Beruf Umwelt 49:85-87

10. Boman A, Wahlberg JE, Johansson G (1982) A method for the study of the effect of barrier creams and protective gloves on the percutaneous absorption of solvents. Dermatologica 164:157-160

11. Boman A, Mellström GA (1989) Percutaneous absorption of 3 organic solvents in the guinea pig (III). Effect of barrier creams. Contact Dermatitis 21:134-140

12. Coenraads PJ, Diepgen TL (2003) Problems with trials and intervention studies on barrier creams and emollients at the workplace. Int Arch Occup Environ Health 76: 362-366

13. Cronin E (1985) Barrier creams. In: Griffith WAD, Wilkinson S (eds) Essentials of industrial dermatology. Blackwell Science, Oxford, pp 106-110

14. De Fraissinette A, Picarles V, Chibout S, Kolopp M, Medina J, Burtin P, Ebelin ME, Osborne S, Mayer FK, Spake A, Rosdy M, de Wever B, Ettlin RA, Cordier A (1999) Predictivity of an in vitro model for acute and chronic skin irritation (SkinEthic) applied to the testing of topical vehicles. Cell Biol Toxicol 15:121-135

15. De Fine Olivarius F, Brinch Hansen A, Karlsmark T, Wulf HC (1996) Water protective effect of barrier creams and moisturizing creams: a new in vivo test method. Contact Dermatitis 35:219-225

16. Diepgen TL (1999) Epidemiological intervention study of skin protection for occupational-stressed skin. 12th International Contact Dermatitis Symposium, 15-18 October 1999, San Francisco, Calif.

17. Elsner P, Wigger-Alberti W, Pantini G (1998) Perfluoropolyethers in the prevention of irritant contact dermatitis. Dermatology 197:141-145

18. Eun HC, Nam C (2003) Alternative methods for evaluating skin irritation using three-dimensional cultures. Exog Dermatol 2:1-5

19. Fowler JF (2000) Efficacy of a skin-protective foam in the treatment of chronic hand dermatitis. Am J Contact Dermat 33:165-169

20. Frosch P, Schulze-Dirks A, Hoffmann M, Axthelm I (1993) Efficacy of skin barrier creams (II). Ineffectiveness of a popular "skin protector" against various irritants in the repetitive irritation test in the guinea pig. Contact Dermatitis 29:74-77

21. Frosch PJ, Kurte A (1994) Efficacy of skin barrier creams (IV) The repetitive irritation test (RIT) with a set of 4 standard irritants. Contact Dermatitis 31:161-168

22. Frosch PJ, Peiler D, Grunert V, Grunenberg B (2003) Efficacy of barrier creams in comparison to skin care products in dental laboratory technicians - a controlled trial. JDDG $1: 547-557$

23. Fullerton A, Menné $T$ (1995) In vitro and in vivo evaluation of the effect of barrier gels in nickel contact allergy. Contact Dermatitis 32:100-106

24. Funke U, Fartasch M, Diepgen TL (2001) Incidence of work-related hand eczema during apprenticeship: first results of a prospective cohort study in the car industry. Contact Dermatitis 44:166-172 
25. Gawkrodger DJ, Healy J, Howe AM (1995) The prevention of nickel contact dermatitis. A review of the use of binding agents and barrier creams. Contact Dermatitis 32 : 257-265

26. Gehring W, Dördelmann C, Gloor M (1994) Effektivitätsnachweis von Hautschutzpräparaten. Allergologie 17: 97-101

27. Gehring W (2004) Das Stratum corneum in vitro - ein Modell zur Entwicklung von Hautschutzpräparaten mit entquellenden Eigenschaften auf die Hornschicht. Derm Beruf Umwelt 52:139-145

28. Gloor M, Gabard B, Fluhr JW, Lehmacher W (2001) Action of an aluminium chlorohydrate and glycerol containing skin protection cream in experimental skin irritation produced by sodium laurylsulfate and solvents. Derm Beruf Umwelt 49:76-70

29. Goh CL (1991) Cutting oil dermatitis on guinea pig skin (I). Cutting oil dermatitis and barrier cream. Contact Dermatitis $24: 16-21$

30. Goh CL, Gan SL (1994) Efficacies of a barrier cream and an afterwork emollient cream against cutting fluid dermatitis in metalworkers: a prospective study. Contact Dermatitis $31: 176-180$

31. Grevelinck SA, Murrell DF, Olsen EA (1992) Effectiveness of various barrier preparations in preventing and/or ameliorating experimentally produced Toxicodendron dermatitis. J Am Acad Dermatol 27:182-188

32. Grunewald A, Gloor M, Gehring W, Kleesz P (1995) Efficacy of skin barrier creams. In: Elsner P, Maibach HI (eds) Irritant dermatitis: new clinical and experimental aspects. Karger, Basel, pp 187-197

33. Guillemin M, Murset JC, Lob M, Riquez J (1974) Simple method to determine the efficiency of a cream used for skin protection against solvents. Br J Ind Med 31:310-316

34. Guin JD (2001) Treatment of Toxicodendron dermatitis (poison ivy and poison oak). Skin Therapy Lett 6:3-5

35. Gupta BN, Shanker R, Viswanathan PN et al (1987) Safety evaluation of a barrier cream. Contact Dermatitis 17:10-12

36. Hogan DJ, Dannaker CJ, Lal S, Maibach HI (1990) An international survey on the prognosis of occupational contact dermatitis of the hands. Derm Beruf Umwelt 38:143-147

37. Jepsen JR, Sparre-Jorgensen A, Kyst A (1985) Hand protection for car-painters. Contact Dermatitis 13:317-320

38. John SM, Uter W, Schwanitz HJ (2000) Relevance of multiparametric skin bioengineering in a prospectively-followed cohort of junior hairdressers. Contact Dermatitis 43:161-168

39. Kelterer Kelterer D, Fluhr JW, Elsner P (2003) Application of protective creams: use of a fluorescence-based training system decreases unprotected areas on the hands. Contact Dermatitis 49:159-160

40. Klotz A, zur Mühlen A, Thörner B, Kietzmann M, Holtmann W, Pittermann W (2003) Testing the efficacy of skin protection products in-vivo and in-vitro. SÖFW J 129: 10-16

41. Korinth G, Geh S, Schaller KH, Drexler H (2003) In vitro evaluation of the efficacy of skin barrier creams and protective gloves on percutaneous absorption of industrial solvents. Int Arch Occup Environ Health 76:382-386

42. Kresken J, Klotz A (2003) Occupational skin-protection products - a review. Int Arch Occup Environ Health 76 : 355-358

43. Kuss O, Diepgen TL (1998) Proper statistical analysis of transepidermal water loss (TEWL) measurements in bioengineering studies. Contact Dermatitis 39:64-67

44. Kutting B, Drexler H (2003) Effectiveness of skin protection creams as a preventive measure in occupational der- matitis: a critical update according to criteria of evidencebased medicine. Int Arch Occup Environ Health 76: 253-259

45. Lachapelle JM (1996) Efficacy of protective creams and/or gels. In: Elsner P, Lachapelle JM, Wahlberg J, Maibach HI (eds) Prevention of contact dermatitis. Current problems in dermatology. Karger, Basel, pp 182-192

46. Lauwerys RR, Dath T, Lachapelle JM, Buchet JP, Roels H (1978) The influence of two barrier creams on the percutaneous absorption of $m$-xylene in man. J Occup Med 20: 17-20

47. Lodén $M$ (1986) The effect of 4 barrier creams on the absorption of water, benzene, and formaldehyde into excised human skin. Contact Dermatitis 14:292-296

48. Löffler H, Effendy I (2002) Prevention of irritant contact dermatitis. Eur J Dermatol 12:4-9

49. Löffler H, Effendy I (2002) Hautschutz- oder Hautregenerationscreme? Der Halbseitenversuch in der Bewertung eines hautpflegenden Externums. Z Hautkr 77: 234-238

50. Lushniak B, Mathias CG, Taylor JS (2003) Barrier creams: fact or fiction? Am J Contact Dermat 14:97-99

51. Mahmoud G, Lachapelle JM, van Neste D (1984) Histological assessment of skin damage by irritants: its possible use in the evaluation of a 'barrier cream'. Contact Dermatitis 11 :179-185

52. Mahmoud G, Lachapelle JM (1985) Evaluation of the protective value of an antisolvent gel by laser Doppler flowmetry and histology. Contact Dermatitis 13:14-19

53. Marks JG Jr, Fowler JF Jr, Sheretz EF, Rietschel RL (1995) Prevention of poison ivy and poison oak allergic contact dermatitis by quaternium-18 bentonite. J Am Acad Dermatol 33:212-216

54. Marks R, Dykes PJ, Hamami I (1989) Two novel techniques for the evaluation of barrier creams. Br J Dermatol 120: $655-660$

55. McCormick RD, Buchmann TL, Maki DG (2000) Doubleblind, randomized trial of scheduled use of a novel barrier cream and an oil-containing lotion for protecting the hands of health care workers. Am J Infect Control 28: 302-310

56. Menné T (1995) Prevention of nickel dermatitis. Allergologie $18: 447$

57. Patterson SE, Williams JV, Marks JG Jr (1999) Prevention of sodium lauryl sulfate irritant contact dermatitis by Pro-Q aerosol foam skin protectant. J Am Acad Dermatol 40: $783-785$

58. Perrenoud D, Gallezot D, van Melle G (2001) The efficacy of a protective cream in a real-world apprentice hairdresser environment. Contact Dermatitis 45:134-138

59. Perrenoud D, Gogniat T, Olmstedt W (2001) Importance of education with appropriate material for the prevention of occupational dermatitis. Derm Beruf Umwelt 49:88-90

6o. Pinola A, Estlander T, Jolanki R, Tarvainen K, Kanerva L (1993) Occupational allergic contact dermatitis due to coconut diethanolamide (cocamide DEA). Contact Dermatitis 29:262-265

61. Pittermann W, Holtmann W, Kietzmann M (2003) Prävention gegen lipophile Noxen durch Hautschutzprodukte. Arbeitsmed Sozialmed Umweltmed 38:435-442

62. Ponec M, Gibbs S, Pilgram G, Boelsma E, Koerten H, Bouwstra J, Mommaas M (2001) Barrier function in reconstructed epidermis and its resemblance to native human skin. Skin Pharmacol Appl Skin Physiol 14 [Suppl 1] : 63-71

63. Ramsing DW, Agner T (1997) Preventive and therapeutic effects of a moisturizer. An experimental study of human skin. Acta Dermato Venereol (Stockh) 77:335-337 
64. Romaguera C, Grimalt F, Vilaplana J et al (1985) Formulation of a barrier cream against chromate. Contact Dermatitis $12: 49-52$

65. Schliemann S, Wigger-Alberti W, Elsner P (1999) Prevention of allergy by protective skin creams: possibilities and limits. Schweiz Med Wochenschr 129:996-1001

66. Schliemann-Willers S, Wigger-Alberti W, Elsner P (2001) Efficacy of a new class of perfluoropolyethers in the prevention of irritant contact dermatitis. Acta Derm Venereol (Stockh) 81:392-394

67. Schliemann-Willers S, Wigger-Alberti W, Kleesz P, Grieshaber R, Elsner P (2002) Natural vegetable fats in the prevention of irritant contact dermatitis. Contact Dermatitis $46: 6-12$

68. Schnetz E, Diepgen TL, Elsner P, Frosch PJ, Klotz AJ, Kresken J, Kuss O, Merk H, Schwanitz HJ, Wigger-Alberti W, Fartasch M (2000) Multicentre study for the development of an in vivo model to evaluate the influence of topical formulations on irritation. Contact Dermatitis 42 : 336-343

69. Schwanitz HJ, Uter W (2000) Interdigital dermatitis: sentinel skin damage in hairdressers. Br J Dermatol 142: 1011-1012

70. Schuppli R, Ziegler G (1967) Neue Möglichkeiten des Hautschutzes gegen Metalle. Z Haut Geschlechtskrankh $42: 345-348$

71. Suskind RR (1955) The present status of silicone protective creams. Indust Med Surg 24:413-416

72. Treffel P, Gabard B, Juch R (1994) Evaluation of barrier creams: an in vitro technique on human skin. Acta Derm Venereol (Stockh) 74:7-11

73. Tronnier H (1964) Über Hautschutzsalben. 1. Mitteilung: Untersuchungen über die Diffusion von Schadstoffen durch Hautschutzsalben. Berufsdermatosen 12:241-281

74. Tronnier H (1993) Methodische Ansätze zur Prüfung von Hautschutzmitteln. Dermatosen 41:100-107

75. Ursin C, Hansen CM, van Dyk JW, Jensen PO, Christensen IJ, Ebbehoej J (1995) Permeability of commercial solvents through living human skin. Am Ind Hyg Assoc J 56: 651-660

76. Uter W, Pfahlberg A, Gefeller O, Schwanitz HJ (1999) Hand dermatitis in a prospectively-followed cohort of hairdressing apprentices: final results of the POSH study. Prevention of occupational skin disease in hairdressers. Contact Dermatitis $41: 280-286$

77. Voss H (1998) Definition und Messung eines Hautschutzfaktors. SÖFW J 124:60-71

78. Wigger-Alberti W, Elsner P (1997) Preventive measures in contact dermatitis. Clin Dermatol 15:661-665

79. Wigger-Alberti W, Maraffio B, Wernli M, Elsner P (1997) Self-application of a protective cream: pitfalls of occupational skin protection. Arch Dermatol 133: 861-864

80. Wigger-Alberti W, Maraffio B, Elsner P (1997) Anwendung von Hautschutpräparaten durch Patienten mit Berufsdermatosen: Notwendigkeit einer verbesserten Verhaltensprävention. Schweiz Med Wochenschr 127:899-904

81. Wigger-Alberti W, Maraffio B, Elsner P (1997) Training workers at risk for occupational contact dermatitis in the application of protective creams: efficacy of a fluorescence technique. Dermatology 195:129-133

82. Wigger-Alberti W, Elsner P (1998) Do barrier creams and gloves prevent or provoke contact dermatitis? Am J Contact Dermat 9:100-106

83. Wigger-Alberti W, Rougier A, Richard A, Elsner P (1998) Efficacy of protective creams in a modified repeated irritation test (RIT): methodological aspects. Acta Derm Venereol (Stockh) 78:270-273
84. Wigger-Alberti W, Caduff L, Burg G, Elsner P (1999) Experimentally-induced irritant contact dermatitis to evaluate the efficacy of protective creams in vivo. J Am Acad Dermatol 40:590-596

85. Wigger-Alberti W, Krebs A, Elsner P (2000) Experimental irritant contact dermatitis due to cumulative epicutaneous exposure to sodium lauryl sulphate and toluene: single and concurrent application. Br J Dermatol 143:551-556

86. Wigger-Alberti W, Elsner P (2000) Barrier creams and emollients. In: Kanerva L, Elsner P, Wahlberg JE, Maibach HI (eds) Handbook of occupational dermatology. Springer, Berlin Heidelberg New York, pp 490-496

87. Wigger-Alberti W, Spoo J, Schliemann-Willers S, Klotz A, Elsner P (2002) The tandem repeated irritation test: a new method to assess prevention of irritant combination damage to the skin. Acta Derm Venereol (Stockh) 82:94-97

88. Wigger-Alberti W, Diepgen TL, Elsner P, Korting HC, Kresken J, Schwanitz HJ (2003) Beruflicher Hautschutz. Gemeinsame Richtlinie der Arbeitsgemeinschaft für Berufs- und Umweltdermatologie (ABD) in der Deutschen Dermatologen Gesellschaft (DDG) und der Gesellschaft für Dermopharmazie e. V. (GD). Derm Beruf Umwelt 51: 15-21

89. Wohrl S, Kriechbaumer N, Hemmer W, Focke M, Brannath W, Gotz M, Jarisch R (2001) A cream containing the chelator DTPA (diethylenetriaminepenta-acetic acid) can prevent contact allergic reactions to metals. Contact Dermatitis $44: 224-228$

9o. Zhai H, Maibach HI (1996) Percutaneous penetration (dermatopharmacokinetics) in evaluating barrier creams. In: Elsner P, Lachapelle JM, Wahlberg J, Maibach HI (eds) Prevention of contact dermatitis. Current problems in dermatology. Karger, Basel, pp 193-205

91. Zhai H, Maibach HI (1996) Effect of barrier creams: human skin in vivo. Contact Dermatitis 35:92-96

92. Zhai H, Willard P, Maibach HI (1998) Evaluating skin-protective materials against contact irritants and allergens. Contact Dermatitis 38:155-158

93. Zhai H, Maibach HI (2000) Barrier creams (skin protective creams). Cosmet Toiletries 115:30-34

94. Zhai H, Maibach HI (2001) Effects of skin occlusion on percutaneous absorption: an overview. Skin Pharmacol Appl Skin Physiol 14:1-10

95. Zhai H, Schmidt R, Levin C, Klotz A, Maibach HI (2001) Prevention and therapeutic effects of a model emulsion on glove-induced irritation and dry skin in man. Derm Beruf Umwelt $50: 134-138$

96. Zur Mühlen A, Klotz A, Weimans S, Veeger M, Thorner B, Diener B, Hermann M (2004) Using skin models to assess the effects of a protection cream on skin barrier function. Skin Pharmacol Physiol 17:167-175 


\subsection{Protective Gloves}

Anders Boman, Gunh A. Mellström

\subsubsection{Introduction}

At the beginning of the 1990's, new directives and regulations concerning the use of and safety requirements for protective gloves came in to force in Europe. Since then the occupational use of protective gloves has increased tremendously, as has the interest in their ability to protect against harmful chemicals and blood-borne infections (such as hepatitis and HIV). In the last few years, the risk of biologi$\mathrm{cal} / \mathrm{chemical}$ warfare agents being released by terrorists has also increased significantly, and so equipment for protecting against and destroying these types of agents are attracting increased interest.

In order to select, purchase and use protective gloves, it is necessary to obtain information on current quality standards, the nature of the hazard(s) encountered, performance data, the acceptable level of exposure to the hazard(s), and any potential adverse effects caused by rubber or plastic protective gloves. Initially, information on the performance of protective gloves could be found in a selection of test reports in the literature. Today, such information is still reported in the literature, but most performance data are now available on the internet, on the websites of glove manufacturers, related authorities and organizations.

\subsubsection{Intended Use of Gloves}

\subsubsection{Protective Gloves}

In Europe, gloves intended to protect the user are referred to as personal protective equipment, and they are covered by the Personal Protective Equipment Directive 89/686/EEC. The EEC Directive states the general requirements for all personal protective equipment, and the requirements for each type of glove have been described previously [23].

Protective gloves are classified into three categories according to the intended use and validation procedures:

Category I: Gloves of a simple design for minimal risk applications

- Category II: Gloves of an intermediate design (not simple or complex) for intermediate risk

- Category III: Gloves of a complex design for irreversible/mortal risks
The requirements for EC-type certification for all categories of gloves are:

A declaration of conformity

A technical documentation file

An affixed CE mark.

For categories II and III there are additional requirements:

EC-type examination testing by approved laboratories, certified by approved notified bodies

- Manufacture under a formal EC quality assurance system

Labeling requirements with pictograms

General requirements for most kinds of protective gloves are defined in the European Standard EN 420. Key aspects are fitness of purpose, nontoxicity, good construction, storage, sizing, adequate glove hand dexterity, and good product information and labeling.

\subsubsection{Medical Gloves}

Gloves intended for use in the medical field to protect patients and users from cross-contamination are referred to as medical devices and are covered by the Council Directive 93/42/EEC concerning such medical devices [23]. A survey of the US rules, regulations and standards concerning the use of protective and medical gloves has been presented by Henry [12].

They are classified into categories:

Surgical gloves

- Examination gloves (sterile or nonsterile)

Foil film gloves

\subsubsection{Selection Procedure}

\subsubsection{Selecting Gloves to Protect Against Chemicals}

Several factors need to be taken into account when selecting a glove for a particular application. The selection process and the factors to be considered in the selection process, such as the work activity and classification of the chemicals encountered, have 
been described for gloves used to protect against chemicals $[15,30]$. The selection procedure, adapted to the EN requirements and standards for protective gloves, is briefly presented in Table 3.1.

\subsubsection{Selecting Gloves to Protect Against Microorganisms}

The selection process and the use of gloves by health care personnel in different working situations has been described by Burman and Fryklund [7] and Ransjö [32]. A scheme for this selection process is presented in Table 3.2. It is based on purpose, working procedure, type of glove (medical gloves or protective gloves), and the risk of exposure to infection or microorganism.

\subsubsection{Glove Materials and Manufacturing}

Today the materials used to manufacture protective gloves are natural rubber, synthetic rubber, textile fibers, leather and several polymeric materials. A survey of glove materials used for protective $(\mathrm{PG})$ and medical gloves (MG) is presented in Table 3.3. Mellström and Boman [22] have presented detailed descriptions of the materials used for glove manufacturing as well as different manufacturing methods and glove types.

The protective effects of different glove materials against hazardous chemicals is dependent on the following factors:

- Thickness: the breakthrough time increases as the thickness of the glove material increases (in a nonlinear fashion, however) [13,35].

- Material composition: chemical resistance capacities vary, even for the same generic material produced by different manufacturers, due to variations in polymer formulation. The barrier effects of different generic materials vary. Each combination of chemical and protective glove material must be considered [27,33]. The quality and protective effects of gloves made from the same material can differ due to different manufacturing processes, additives and quality control $[22,31]$.

Table 3.1. Glove selection: protective gloves

\begin{tabular}{|c|c|c|}
\hline $\begin{array}{l}\text { Gloves needed } \\
\text { and requirements }\end{array}$ & Degree of exposure & Chemical classification and risk of skin injury \\
\hline Cat. I & Risk of exposure, possible splashing & $\begin{array}{l}\text { Mainly contact with chemicals classified as toxic, } \\
\text { harmful or irritant }\end{array}$ \\
\hline $\begin{array}{l}\text { No testing of the protective } \\
\text { effect is required }\end{array}$ & $\begin{array}{l}\text { Occasional, repeated and expected } \\
\text { exposure } \\
\text { Minimal risk only of slight injuries }\end{array}$ & \\
\hline Cat. II & $\begin{array}{l}\text { Occasional, repeated and expected } \\
\text { exposure }\end{array}$ & $\begin{array}{l}\text { Mainly contact with chemicals classified as toxic, } \\
\text { harmful or irritant }\end{array}$ \\
\hline $\begin{array}{l}\text { Breakthrough time }(\mathrm{BT}) \\
\text { and/or permeation rate }(\mathrm{PR}) \\
\text { is required }\end{array}$ & $\begin{array}{l}\text { Continuous exposure at certain times, } \\
\text { expected or accidental } \\
\text { Intermediate risk of moderate, } \\
\text { reversible injuries }\end{array}$ & \\
\hline Cat. III & $\begin{array}{l}\text { Continuous exposure at certain times, } \\
\text { expected or accidental }\end{array}$ & $\begin{array}{l}\text { Mainly contact with chemicals classified as highly } \\
\text { toxic, highly corrosive, corrosive, and with agents } \\
\text { causing cancer, sensitization, or those absorbed } \\
\text { through the skin }\end{array}$ \\
\hline $\begin{array}{l}\text { Breakthrough time }(\mathrm{BT}) \\
\text { and/or permeation rate }(\mathrm{PR}) \\
\text { are required }\end{array}$ & $\begin{array}{l}\text { High risk of severe or irreversible } \\
\text { injuries }\end{array}$ & \\
\hline $\begin{array}{l}\text { In addition, also test results } \\
\text { from performing the glove task }\end{array}$ & & \\
\hline
\end{tabular}


Table 3.2. Glove selection: medical gloves

\begin{tabular}{|c|c|c|}
\hline $\begin{array}{l}\text { Protection of personnel from hepatitis } \\
(\mathrm{A}, \mathrm{B}, \mathrm{C}) \text {, HIV, HTLV }\end{array}$ & $\begin{array}{l}\text { Protection of personnel and patients } \\
\text { from various viruses and bacteria }\end{array}$ & $\begin{array}{l}\text { Protection of patients from hepatitis, } \\
\text { HIV and other viruses and bacteria }\end{array}$ \\
\hline Surgical glove: surgery & $\begin{array}{l}\text { Protective gloves: handling of feces, } \\
\text { urine, vomit, and so on }\end{array}$ & Surgical glove: surgery \\
\hline $\begin{array}{l}\text { Examination gloves, nonsterile: } \\
\text { dentistry, risk of contact with blood } \\
\text { procedures }\end{array}$ & & Examination gloves, sterile: invasive \\
\hline \multirow[t]{2}{*}{$\begin{array}{l}\text { Protective gloves (such as domestic } \\
\text { gloves): risk of contact with blood }\end{array}$} & & $\begin{array}{l}\text { Examination gloves, nonsterile: } \\
\text { dentistry, isolation, barrier nursing }\end{array}$ \\
\hline & & $\begin{array}{l}\text { Protective gloves: isolation, handling of } \\
\text { feces, urine, vomit, and so on }\end{array}$ \\
\hline
\end{tabular}

Table 3.3. Survey of glove materials used for protective and medical gloves ( $P G$ protective glove, $M G$ medical glove for single use)

\begin{tabular}{ll} 
Material name/Trade name(s) & Intended use \\
Natural rubber (Latex) & PG and MG \\
Synthetic rubber materials & \\
Polyisoprene & MG \\
Butyl rubber & PG \\
Chloroprene / Neoprene & PG and MG \\
Fluor rubber / Viton & PG \\
Nitrile rubber / Nitrilite, N-Dex & PG \\
Styrene-butadiene & MG \\
Styrene-ethylene-butadiene & MG \\
Plastic polymeric materials & \\
Polyisocyanate urethane & PM and MG \\
EMA (ethylene-methylacrylate) & PG and MG \\
Polyethylene, polythene (PE) & PG and MG \\
Polyvinyl chloride (PVC) & PG and MG \\
PE/EVAL/PE, laminate / 4H/Silver Shield glove & PG \\
Leather & PG \\
Textile: & PG \\
Cotton, nylon, jersey & PG, inner gloves \\
Fiber materials / Kevlar, Lycra and Spectra fiber & Used in jersey surgical inner gloves, cut resistant \\
\hline
\end{tabular}

\subsubsection{Testing the Protective Glove Barrier}

If protective gloves and medical gloves intended for single use are required to give an adequate level of protection, their properties must be tested and evaluated.

\subsubsection{Standard Test Methods}

The most relevant standard test methods for protective gloves and medical gloves are presented in Tables 3.4 and 3.5. Standard test methods are revised on a regular basis, and some former EN standards have now become EN-ISO standards.

In Europe, the testing is performed in a standardized way, by approved laboratories, certified by approved and notified bodies. The test results should be compared with others performed in a similar way. The standard test procedure is not supposed to illustrate the working situation.

When testing gloves in a nonstandardized way, in order to illustrate a certain working situation or extreme working conditions, approved test laboratories, glove manufacturers and consulting companies in the field can give advice and/or design and perform an appropriate testing procedure. 
Table 3.4. Relevant standard test methods for gloves that protect against chemicals (EN European Standard from the European Committee for Standardization, ASTM American Society of Testing and Materials)

\begin{tabular}{|c|c|}
\hline Document number & Title \\
\hline ASTM F 739 & $\begin{array}{l}\text { Standard test methods for resistance of protective clothing materials to permeation by liquids and } \\
\text { gases under conditions of continuous contact }\end{array}$ \\
\hline ASTM F 1383 & $\begin{array}{l}\text { Standard test method for resistance of protective clothing materials to permeation by liquids and } \\
\text { gases under conditions of intermittent contact }\end{array}$ \\
\hline ASTM F 903 & Standard test method for resistance of protective clothing materials to penetration by liquids \\
\hline EN 420 & General requirements for gloves \\
\hline EN 374 & Protective gloves against chemicals and microorganisms: \\
\hline Part 1 & Terminology and performance requirements \\
\hline Part 2 & Determination of resistance to penetration \\
\hline Part 3 & Determination of resistance to permeation by chemicals \\
\hline
\end{tabular}

Table 3.5. Relevant standard test methods for medical gloves (EN European Standard from the European Committee for Standardization, ASTM American Society of Testing and Materials)

\begin{tabular}{ll} 
Document number & Title \\
\hline ASTM D 3577 & Standard specification for rubber surgical gloves \\
ASTM D 3578 & Standard specification for rubber examination gloves \\
ASTM D 5151 & Standard test method for detection of holes in medical gloves \\
ASTM D 5250 & Standard specification for polyvinyl chloride gloves for medical application \\
ASTM D 5712 & Standard test method for analysis of protein in natural rubber and its products \\
EN 455 & Medical gloves for single use: \\
Part 1 & Requirements and testing for freedom from holes \\
Part 2 & Requirements and testing for physical properties \\
Part 3 & Requirements and testing for biological evaluation \\
\hline
\end{tabular}

\section{Physical Properties}

In the EN and ASTM standard specifications, requirements and test methods are given, such as sampling and selection of test pieces, physical dimensions with length, strength and thickness, load for breaking before and after accelerated ageing. The barrier effect is also affected by the storage conditions, and this is particularly important for medical gloves made of natural rubber latex.

\section{Penetration (Leakage)}

Penetration of chemicals and/or microorganisms is a process which can be defined as the flow through closures, porous materials, seams and pinholes or other imperfections in a protective or medical glove material, at a nonmolecular level. Leakage can lead to uncontrolled contact with hazardous chemicals or infectious materials; especially in the healthcare field. Penetration test methods for protective gloves and leakage testing for medical gloves have been described by Mellström et al [26]. As a rule, leakage tests include a random sampling procedure where a certain number of gloves are filled with a specified volume of water or air. These are pass or fail tests, and the number of gloves allowed to fail per number of gloves tested is dependent upon the batch or lot size. The sampling procedure for inspection by attributes defined by the International Organization for Standardization (ISO 2859 should be used.

There are several standardized leakage test methods designed for medical gloves that have been evaluated, and all test methods have inherent limitations [8-10]. In an overview, Schroeder et al [36] presented standard quality control testing and virus penetration. The standard tests used for glove integrity and virus penetration through used and intact gloves are discussed, as well as those used to test penetration through punctures in gloves. Tests used to evaluate the barrier integrity fall into two categories: 
- Those intended to ensure quality during and after manufacturing

- Those tests that challenge the barrier with viral or chemical agents.

They concluded that latex gloves provided significant barrier protection against very small viruses, and that apparent barrier integrity cannot ensure safety, but current quality control protocols ensure that medical gloves provide significant protection.

\section{Permeation}

The permeation is usually described as the process by which a chemical migrates through the protective clothing material on a molecular level, including sorption, diffusion and desorption processes. The principle of permeation standard testing is a flowthrough system where a two-compartment permeation cell of standard dimensions is used. The test specimen acts as barrier between the first compartment of the cell, which contains the test chemical, and the second compartment through which a stream of the collecting medium (gas or liquid) is passed. The collecting medium will collect the diffused molecules of the test chemical or its component chemicals for analysis. The standard methods defined in EN-374:3 and those of the corresponding ASTM F-739 standard have now been harmonized and are considered equivalent.

The key parameters measured for permeability are usually:

Breakthrough time (BT, min): in the ASTM and EN standard test methods, the breakthrough time is defined as the time when a specified permeation rate is reached

- Permeation rate (PR): the mass of test chemical permeating the material per unit time per unit area $\left(\mu \mathrm{g} \cdot \mathrm{min}^{-1} \cdot \mathrm{cm}^{-2}\right)$

- Steady-state permeation (SP): a state that is reached when the permeation rate becomes virtually constant.

In the European Standard for gloves used to protect against chemicals and microorganisms, one of the requirements is that the protective effect of a particular combination of protective glove/test chemical should be presented as a protection index. The protection index is based on the breakthrough time measured for constant contact with the test chemical (European Standard EN 374-1). See Table 3.6.
Table 3.6. Index based on breakthrough times determined during constant contact with the test chemical described in European Standard EN 374-3

\begin{tabular}{ll} 
Protection Index & Measured breakthrough time (min) \\
\hline Class 1 & $>10$ \\
Class 2 & $>30$ \\
Class 3 & $>60$ \\
Class 4 & $>120$ \\
Class 5 & $>240$ \\
Class 6 & $>480$ \\
\hline
\end{tabular}

\section{Biocompatibility}

Over the last few years, the number of severe adverse reactions caused by latex products (such as latex proteins in gloves) in health care workers has risen significantly. Adverse reactions due to rubber chemicals, powder, lubricants, endotoxins and pyrogens are well known and are more frequent than reactions to proteins. In Europe, the requirements and test methods for biological evaluations of medical gloves have been defined and the EN 455 standard (Medical gloves for single use. Part 3: Requirements and testing for biological evaluation) is now in force. Results from the test and applied test methods are to be made available on request.

\subsubsection{In Vivo Testing}

Additional information on the protective efficacy of gloves can be derived from in vivo testing in man or in experimental animals [38]. For screening, an animal model can be used for comparative investigation of the protective effects of gloves $[5,6]$. In work-related studies, the effects of exposure to potentially hazardous chemicals used in the workplace are studied. Protective effects and side effects of gloves can be studied by patch testing contact allergic individuals with the specific allergen together with pieces of glove $[2,3,16]$.

\subsubsection{Protective Effects of Gloves}

\subsubsection{Protection Against Microorganisms}

A number of studies of the barrier effect of gloves against microorganisms, performed using various test methods during the period 1976-1993, have been reviewed by Hamann and Nelson [11]. Their conclu- 
sions were that the barrier effect of the gloves is dependent on a complex interaction of several factors:

Type and brand of glove (latex or plastic materials)

- Condition of use (unused, stimulated use or in actual clinical situations)

- Sensitivity of the assay (water-, air-, dye-leak tests, bacterial or viral penetration)

They also concluded that some trends could be seen in the data, such as:

The material is an important determinant of the glove barrier

The brand of glove influences the outcome of barrier testing

- The quality of a glove is more closely related to the manufacturer than to the glove material

- Leakage rates are related to the level of use a glove receives

- The efficacy of the glove barrier varies with the sensitivity of the testing procedure

\subsubsection{Protection Against Some Chemical Agents Hazardous to the Skin}

In both Europe and in the US there are comprehensive guides, with classifications of hazardous chemicals of all kinds. The risk codes and safety phrases are usually given in the safety data sheets for the actual chemical, and this sheet should always be made available by the supplier of the chemical.

\section{Disinfectants}

Disinfectants are generally used to clean surfaces and objects and for the cold sterilization of instruments. The use of different kinds of disinfectants is frequent for the preoperative skin disinfection of patients and in working situations where there is a risk of acquiring blood-borne infections. In these circumstances it is important to use gloves, both to protect the skin against infections and to avoid contact with disinfectants harmful to the skin. Some of these agents are known to cause allergic and/or irritant reactions after contact with the skin; for example ethanol, isopropyl alcohol, chlorocresol and glutaraldehyde. The influence of four disinfectant products on six different brands of medical gloves, evaluated by measuring the permeation and through SEM (Scanning Elec- tronic Microscopy) studies of the exposed glove material surfaces, has been described by Mellström et al [24]. They found that gloves made from latex, PVC and polyethylene gave acceptable protection from contact with $p$-chloro- $m$-cresol (Blifacid) and glutaraldehyde (Cidex) containing products for at least $60 \mathrm{~min}$, but did not provide acceptable protection from contact with isopropanol and ethanol. Recent studies also show that they provide inadequate protection from formaldehyde $[17,20,21]$.

\section{Pharmaceuticals}

Pharmaceutical preparations of drugs, e.g., cytostatic agents have very heterogeneous mechanism of action, they have potent pharmacological properties and it is well known that they can cause acute skin injuries in cases of accidental exposure [14]. The extent of health hazard due to chronic exposure to small amounts of cytostatic drugs by personnel is still not completely known and therefore it is necessary to minimize the exposure. In order to minimize the risk of contact when preparing, dispensing and administrating these drugs, a standard procedure, appropriate technique together with personal protective equipment, e.g., gloves should be used. However, there are no requirements or criteria for evaluating medical glove quality for this purpose of use [25]. Several cytostatic drugs penetrated latex gloves [17, 37].

\section{Composite Materials (Bone Cement, Dental Filling Materials)}

The increased use of acrylic compounds as a substitute for amalgam by dentists, dental nurses and dental technicians has resulted in an increased frequency of hand eczema for these groups. This is a serious problem because there are currently no commercially available gloves that have the required dexterity but that also provide sufficient protection for the skin. Standard procedures, appropriate techniques, and packaging design together with adjusted personal protective gloves are urgently required. In several studies of the permeability of medical gloves to methacrylates in resinous dental material, no gloves were impervious, but nitrile and chloroprene showed a little more resistance than other glove materials [4, $17,18,28,29]$. However, it is important to note that the use of acetone as a solvent in a bonding material may reduce the protective effect markedly. The combined use of latex gloves with $4 \mathrm{H} /$ Silver Shield gloves as an inner glove may be useful in some working situations. The protective efficacies of seven different nonlatex gloves against a dental bonding product 
containing 2-HEMA were evaluated on eight patients with a test-verified contact allergy to 2-HEMA. Gloves made of neoprene gave the best protection, and gloves made of polyethylene gave comparable results to the positive control (no gloves) $[2,3]$.

\section{Solvents}

Alcohol and other aliphatic and aromatic organic solvents have a degreasing and irritating effect on the skin, and can be absorbed through the skin into the blood. For splashes or very short contact times (10-30 min), gloves made of natural rubber, PE or PVC can be useful for protecting against these solvents. For occasional (30-6o $\mathrm{min}$ ) and intentional exposure, gloves made of nitrile rubber, natural rubber or neoprene rubber can be useful, while for intentional exposure for extended periods $(>60 \mathrm{~min})$, $4 \mathrm{H} /$ Silver Shield-gloves, Viton or butyl rubber should be used.

\section{Corrosive Agents}

Short repeated exposures or an extended exposure to small amounts of corrosive substances and oxidizing/reducing agents, acids, bases and concentrated salt solutions can cause severe irritation to the skin. Glove materials suitable for protecting from brief exposure (10-30 $\mathrm{min}$ ) to this kind of hazardous chemical are natural rubber, PE and PVA. Occasional but intentional exposure (for 30-60 $\mathrm{min}$ ) requires gloves made of neoprene, natural rubber or nitrile rubber. Intentional exposure for extended periods ( $>60 \mathrm{~min}$ ) necessitates butyl rubber, Viton or $4 \mathrm{H} /$ Silver Shield gloves.

\section{Detergents, Surfactants, Cleansers}

Washing-up liquids, cleaning agents and soaps are usually water-based and cause only mild effects to the skin when used in recommended concentrations; however, when used at high concentrations they can cause skin injuries. Sometimes organic solvents like white spirit or isopropanol are added. For splashes or very short contact times (10-30 min), gloves made of EMA, PE or PVC are useful. For occasional but intentional (30-60 $\mathrm{min}$ ) exposure, gloves made of natural rubber, neoprene or PVC are useful, while extended exposure ( $>60 \mathrm{~min}$ ) necessitates gloves made of natural rubber, neoprene or PVC. If organic solvent is added, then gloves made of nitrile rubber should be used.

\section{Oils, Cutting Fluids, Lubricant Oils}

These agents often contain anticorrosive agents, bactericides and antioxidants. Oils can contain small amounts of chromium, nickel and cobalt. For splashes or very short contact times (10-30 min), gloves made of natural rubber or PVC gloves can be useful. Occasional but intentional (30-60 $\mathrm{min}$ ) exposure requires industrial gloves made of nitrile rubber, natural rubber or neoprene, while intentional exposure for extended periods ( $>60 \mathrm{~min}$ ) necessitates $4 \mathrm{H} / \mathrm{Sil}$ ver Shield gloves or nitrile rubber gloves.

Warning! When working at machinery with rotating and moving parts, using gloves can increase the risk of tear injuries and so they should be used with caution.

\subsubsection{Information Sources}

\subsubsection{Internet}

The easiest way to get information on the performance of protective gloves intended for use when working with hazardous chemicals is to search on the internet. Most glove manufacturers have a selection guide/selection procedure and performance data for gloves of all categories on their websites. Related authorities and organizations, and universities, have useful information on standards, test reports, and links to, for example, glove-chemical compatibility guides. Below are some website addresses that may be useful during the selection procedure. Since the Web is a dynamic source of information, these URLs may change, so it may be necessary to make use of search engines to find the data required.

\section{Glove Manufacturer Websites}

AnsellPro Gloves (http://www.ansell-edmont.com)

- Ansell Healthcare (http://www.ansellhealthcare.com)

- Best Gloves (http://www.bestglove.com)

- Comasec (http://www.comasec.com)

- Mapa Gloves (http://www.mapaglove.com)

- Marigold Industrial (http://www.marigoldindustrial.com)

North Safety Products (http://www.northsafety.com) 


\section{Websites of Some Related Authorities} andOrganizations

ASTM International (http://www.astm.org)

European Committee for Standardisation (http://www.cenorm.be)

- National Institute for Occupational Safety and Health (http://www.cdc.gov/niosh)

- OSCHA (http://www.oscha.gov)

- AIHA Laboratory Health and Safety Committee (http://www2.umdnj.edu/eohssweb/ aiha/technical/ppe.htm)

- Eurofins Scientific (http://www.eurofins.com)

\subsubsection{Bibliographic Data}

Useful and relevant information is also still available in scientific journals (many of which are on the internet), handbooks and guide books, as well as in test reports.

\subsubsection{Limitations on Use Due to Side-Effects, and Therapeutic Alternatives}

Allergic reactions to gloves can be caused by, for example, rubber chemicals, organic pigments, and latex proteins. Irritant reactions to gloves are caused by, say,. mechanical stress, endotoxins, ethylene dioxide and glove powder. Side effects can also occur from contact with glove powder, such as starch-induced adhesions and granulomas following surgery.

Risks and side effects from the use of gloves are described in detail in other chapters in this book.

\subsubsection{Gloves Made From Synthetic Materials}

The use of gloves made from polymer materials is necessary both when treating patients and when employees have a known allergy to latex proteins, in order to reduce the risk of contact dermatitis caused by rubber additives as well as of contact urticaria from latex proteins. Gloves made from polymer materials are also needed by employees with known allergies to the chromate in leather gloves.

\subsubsection{Double Gloving}

Using natural rubber latex gloves with inner gloves made from plastic material, nylon or cotton reduces the risk of contact dermatitis and urticaria caused by latex rubber gloves

- Using natural rubber latex gloves with synthetic fiber gloves reduces the risk of cut and puncture injuries

- Using natural rubber latex gloves with latex or plastic gloves reduces the risk of blood-borne infections and/or chemical permeation

\subsubsection{Powder-Free Gloves}

Powder-free gloves should be used to reduce the risk of symptoms from rhinitis, conjunctivitis, urticaria and asthma caused by glove powder contaminated by latex proteins.

\subsubsection{Conclusions}

Important factors that should be considered during the selection procedure include:

Nature of the work task and risk of exposure

Length of work

- Mechanical quality of the glove material (tensile strength, dexterity, cut, tear and puncture resistance).

- Resistance to penetration and permeation of hazardous chemicals and microorganisms

- Risk of adverse effects when using a specific glove (allergic contact dermatitis, contact urticaria, irritation, itching, and so on)

- Function (using the gloves must not create another risk or be a hindrance)

- Comfort, fit, "wearability"

Quality (and whether the quality is maintained for every glove), price

The large number of factors suggests that the selection procedure can be rather complicated! 


\section{References}

1. Andersson T, Bruze M (1999) In vivo testing of the protective efficacy of gloves against allergen-containing products using an open chamber system. Contact Dermatitis $41: 260-263$

2. Andersson T, Bruze M, Björkner B (1999) In vivo testing of the protection of gloves against acrylates in dentin-bonding systems on patients with known contact allergy to acrylates. Contact Dermatitis 41:254-259

3. Andersson T, Bruze M, Gruvberger B, Björkner B (2000) In vivo testing of the protection provided by nonlatex gloves against a 2-hydoxyethyl methacrylate-containing acetonebased dentin-bonding product to acrylates. Acta Derm Venereol (Stockh) 80:435-437

4. Andreasson H, Boman A, Johnsson S, Karlsson S, Barregård L. (2003) On permeability of methyl methacrylate, 2hydroxyethyl methacrylate and triethyleneglycol dimethacrylate through protective gloves in dentistry. Eur J Oral Sci 111:529-535

5. Boman AS, Mellström GA (1989) Percutaneous absorption of three organic solvents in the guinea pig. IV. Effect of protective gloves. Contact Dermatitis 21:260-266

6. Boman AS, Mellström GA (1994) Percutaneous absorption studies in animals. In: Mellström GA, Wahlberg JE, Maibach HI (eds) Protective gloves for occupational use. CRC Press, Boca Raton, FL, pp 91-107

7. Burman LG, Fryklund B (1994) The selection and use of gloves by health care professionals. In: Mellström GA, Wahlberg JE, Maibach HI (eds) Protective gloves for occupational use. CRC, Boca Raton, Fla., pp 283-292

8. Carey R, Herman W, Herman B, Casamento J (1989) A laboratory evaluation of standard leakage tests for surgical and examination gloves. J Clin Eng 14:133-143

9. Douglas AA, Neufeld PD, Wong RKW (1992) An interlaboratory comparison of standard test methods for medical gloves. In: McBriarty JP, Henry N (eds) Performance of protective clothing, vol 4. ASTM STP 1133, American Society for Testing and Materials, Philadelphia, pp 99-113

10. Douglas A, Simon TR, Goddard M (1997) Barrier durability of latex and vinyl medical gloves in clinical settings. Am Ind Hyg Assoc J 58:672-676

11. Hamann CP, Nelson JR (1993) Permeability of latex and thermoplastic elastomer gloves to the baceteriophage Phi X 174. Am J Infect Control 21:289-296

12. Henry NW III (2004) US rules, regulations and standards for protective gloves for occupational use. In: Boman A, Estlander T, Wahlberg JE, Maibach HI (eds) Protective gloves for occupational use, 2nd edn. CRC, Boca Raton, Fla., pp 35-41

13. Jencen DA, Hardy JK (1989) Effect of glove material thickness on permeation characteristics. Am Ind Hyg Assoc J $50: 623-626$

14. Knowles RS, Virden JE (1980) Occasional review. Handling of injectable antineoplastic agents. Br Med J 30:589-591

15. Leinster $P$ (1994) The selection and use of gloves against chemicals. In: Mellström GA, Wahlberg JE, Maibach HI (eds) Protective gloves for occupational use. CRC, Boca Raton, Fla., pp 269-281

16. Lidén C, Wrangsjö K (1994) Protective effect of gloves illustrated by patch test testing-practical aspects. In: Mellström GA, Wahlberg JE, Maibach HI (eds) Protective gloves for occupational use. CRC, Boca Raton, Fla., pp 207-212

17. Mäkelä E A, Jolanki R (2004) Chemical permeation through disposable gloves. In: Boman A, Estlander T, Wahlberg JE, Maibach HI (eds) Protective gloves for occupational use, 2nd edn. CRC, Boca Raton, Fla., pp 299-314
18. Mäkelä EA et al (1992)

19. Mäkelä EA, Väänänen V, Alanko K, Jolanki R, Estlander T, Kanerva L (1999) Resistance of disposable gloves to permeation by 2-hydroxymethacrylate and triethylene glycoldimethacrylate. Occup Hyg 582:121-129

20. Mäkelä EA, Vainiotalo S, Peltonen K (2003a) The permeability of surgical gloves to seven chemicals commonly used in hospitals. Ann Occup Hyg 47:313-323

21. Mäkelä EA, Vainiotalo S, Peltonen K (2003b) Permeation of $70 \%$ isopropyl alcohol through surgical gloves: comparison of the standard methods ASTM F739 and EN 374. Ann Occup Hyg 47:305-312

22. Mellström GA, Boman A (2004) Gloves: types, materials, and manufacturing. In: Boman A, Estlander T, Wahlberg JE, Maibach HI (eds) Protective gloves for occupational use use, 2nd edn. CRC, Boca Raton, Fla., pp 15-28

23. Mellström G A, Carlsson B (2004) European Standards on protective gloves. In: Boman A, Estlander T, Wahlberg JE, Maibach HI (eds) Protective gloves for occupational use, 2nd edn. CRC, Boca Raton, Fla., pp 29-33

24. Mellström GA, Lindberg M, Boman A (1992) Permeation and destructive effects of disinfectants on protective gloves. Contact Dermatitis 26:163-170

25. Mellström GA, Wrangsjö K, Wahlberg JE, Fryklund B (1996) The value and limitation on gloves in medical health service, part II. Dermatol Nursing $8: 287-295$

26. Mellström GA, Carlsson B, Boman A (2004) Testing of protective effect against liquid chemicals. In: Boman A, Estlander T, Wahlberg JE, Maibach HI (eds) Protective gloves for occupational use, 2nd edn. CRC, Boca Raton, Fla., pp 71-87

27. Mickelsen RL, Hall RC (1987) A breakthrough time comparison of nitrile and neoprene glove materials produced by different glove manufacturers. Am Ind Hyg Assoc J 48 : 941-947

28. Munksgaard EC (1992) Permeability of protective gloves to (di) methacrylates in resinous dental materials. Scand J Dent Res 100:189-192

29. Munksgaard EC (2000) Permeability of protective gloves by HEMA and TEGDMA in the presence of solvents. Acta Odontol Scand 58:57-62

30. Packham CL, Packham HE (2004) Practical considerations when selecting and using gloves for chemical protection in a workplace. In: Boman A, Estlander T, Wahlberg JE, Maibach HI (eds) Protective gloves for occupational use, 2nd edn. CRC, Boca Raton, Fla., pp 255-285

31. Perkins JL, Pool B (1997) Batch lot variability in permeation trough nitrile gloves Am Ind Hyg Assoc J 58:474-479

32. Ransjö U (2004) Gloves as protection against microbial contamination. In: Boman A, Estlander T, Wahlberg JE, Maibach HI (eds) Protective gloves for occupational use, 2nd edn. CRC, Boca Raton, Fla., pp 315-320

33. Sansone EB, Tewari YB (1980) Differences in the extent of solvent penetration through natural rubber and nitrile gloves from various manufacturers. Am Ind Hyg Assoc J 41:527-528

34. Schwope AD, Costas PP, Jackson JO, Weitzman JO (1985) Guidelines for the selection of protective clothing. American Conference of Governmental Industrial Hygienists, Cincinnati

35. Schwope AD, Costas PP, Mond CR, Nolen RL, Conoley M, Garcia DB, Walters DB, Prokopetz AT (1988) Gloves for protection from aqueous formaldehyde: permeation resistance and human factors analysis. Appl Ind Hyg 3:167-176

36. Schroeder LW, Walsh DL, Schwerin MR, Richardson DC, Kisielewski RW, Cyr WH (2004) In: Boman A, Estlander T, Wahlberg JE, Maibach HI (eds) Protective gloves for occupational use, 2nd edn. CRC, Boca Raton, Fla., pp 89-109 
37. Sessink PJM, van de Kerkhof MCA, Anzion RB, Bos RP (1994) Environmental contamination and assessment of exposure to antineoplastic agents by determination of $\mathrm{Cy}$ clophosphamide in urine of exposed pharmacy technicians: Is skin absorption an important exposure route? Arch Environ Health 4:165-169

38. Svedman C, Bruze M (2004) In vivo testing of the protective effect of gloves. In: Boman A, Estlander T, Wahlberg JE, Maibach HI (eds) Protective gloves for occupational use, 2nd edn. CRC, Boca Raton, Fla., pp 111-119

\subsection{Worker Education} and Teaching Programs

\subsubsection{The German Experience}

Britta Wulfhorst, Meike Bock, Christoph Skudlik, Swen Malte John ${ }^{1}$

\subsubsection{Introduction}

The number of work-related skin disorders has decreased in the last few years. However, despite the detailed knowledge available on their pathogenesis, diagnosis and therapy, they remain extraordinarily common, necessitating continual care for employees in "wet work" jobs, since they are a high-risk group for work-related skin disorders and allergies [24, 28, 32].

In this chapter we describe a range of interdisciplinary prevention strategies for work-related skin disorders, comprising both medical and educational measures. This integrative approach was developed using a framework of different projects investigating primary, secondary and tertiary prevention of occupational skin disorders. The theoretical basis for these projects was predominantly the World Health Organization's definition of health promotion [33]. In order to meet the requirements of the WHO for health promotion, including self-determination, autonomy, and the social responsibilities of the individual and the social environment, it is necessary to design preventive strategies concerning work-place conditions at an individual level $[29,20]$. The efficacy of such measures is evaluated using the example of affected skin. In addition to adequate dermatological diagnosis and therapy for acute and chronic skin changes, the task of prevention also includes clarifying, for those at risk, the correlation between health risks and their own ability to act in order to protect themselves. This knowledge should then lead to individual empowerment [33].

\footnotetext{
1 This chapter is dedicated to our highly respected academic teacher Professor Hans Joachim Schwanitz
}

\subsubsection{Primary Prevention of Occupational Contact Dermatitis}

Hairdressers belong to an occupational group that is commonly affected by occupational skin disease. Occupational contact dermatitis predominantly affects apprentices $[28,31]$. In order to prevent occupational skin changes in hairdressing trainees, an intervention study was performed between 1996 and 1999. Comprising medical and educational intervention, this study was based upon interdisciplinary concepts [23].

\section{Methods}

The study concentrated on hairdressers' apprentices who started their vocational training in 1996. The participants of the intervention group were pupils of a vocational school in Osnabrück, while participants of the matched control group were pupils of a vocational school in Hannover (both schools were in Lower Saxony, Germany). During their vocational training, all of the participants were examined four times by a dermatologist. Their skin conditions were recorded using standardized scores [31]. Participants of the intervention group participated in six seminars (15 hours of lessons), held by professional educators. Therefore, these participants were specifically trained in skin care management and the prevention of occupational contact dermatitis. Moreover, they were supplied with the necessary skin care products, such as gloves and specific protective creams. Consultations about their work environments were also offered and given. Using written questionnaires, knowledge and attitudes concerning skin care management were checked in both the interventional group and the control group at the beginning and end of their second "school year". Statistically significant differences $(p<0.05)$ in skin conditions were analyzed using the Wilcoxon Signed-Rank Test for grouped data. Statistically significant results gained from questionnaires on the attitudes, knowledge and behavior regarding skin care were analyzed using Mann-Whitney and Wilcoxon $U$-tests.

\section{Results}

The incidence of occupational contact dermatitis in both groups was comparable in the year 1997 (Table 4.1). In $199890 \%$ of the participants from the interventional group and $75 \%$ of those from the control group had no skin changes (Table 4.1). These differences were significant $(p<0.05)$. At the end of the training program $80 \%$ of the intervention group and $66 \%$ of the control group had encountered no skin 
Table 4.1. Results of the Osnabrück Intervention Study 1996 ( I Interventions group, $C$ Control group, $o$ nothing, 1 mild, 2 moderate, 3 severe)

\begin{tabular}{|c|c|c|c|c|c|c|c|c|c|c|c|c|c|c|c|c|c|}
\hline \multirow[t]{2}{*}{ Parameter } & \multirow[t]{2}{*}{ Response } & \multicolumn{4}{|c|}{1996} & \multicolumn{4}{|c|}{1997} & \multicolumn{4}{|c|}{1998} & \multicolumn{4}{|c|}{1999} \\
\hline & & I & $\%$ & C & $\%$ & I & $\%$ & C & $\%$ & I & $\%$ & $\mathrm{C}$ & $\%$ & I & $\%$ & C & $\%$ \\
\hline$(n)$ & & 73 & & 112 & & 50 & & 73 & & 39 & & 48 & & 41 & & 56 & \\
\hline Skin changes & 0 & 63 & 86.3 & 81 & 72.3 & 28 & 56 & 41 & 56.2 & 35 & 90 & 36 & 75 & 33 & 80.5 & 37 & 66.1 \\
\hline \multirow[t]{3}{*}{ Severity } & 1 & 10 & 13.7 & 26 & 23.3 & 19 & 38 & 22 & 30.1 & 4 & 10 & 8 & 16.7 & 7 & 19.5 & 11 & 19.6 \\
\hline & 2 & 0 & & 2 & 1.8 & 2 & 4 & 5 & 6.8 & 0 & & 3 & 2.1 & 0 & & 7 & 12.5 \\
\hline & 3 & 0 & & 3 & 2.7 & 1 & 2 & 5 & 6.8 & 0 & & 1 & 6.3 & 0 & & 1 & 1.8 \\
\hline
\end{tabular}

changes (Table 4.1). Concerning the severity of skin changes, no statistical significant differences were observed in either the intervention or the control group at the beginning (1996) of the study (Table 4.1). Furthermore, the incidence of OCD of both groups was comparable in 1997 (Table 4.1). 90\% of the participants from the interventional group and $75 \%$ from the control group had encountered no skin changes in 1998 (Table 4.1). These differences were significant $(p<0.05)$. At the end of the training program (1999), $80 \%$ of the participants from the intervention group and $66 \%$ from the control group had encountered no skin changes (Table 4.1).

\subsubsection{Secondary Prevention of Occupational Contact Dermatitis}

\section{Secondary Prevention Project for Hairdressers}

A job-specific secondary prevention program was created to enable hairdressers to remain at work despite their skin problems. Again, an interdisciplinary and integrative approach comprising both medical and educational measures, using the concept of an intervention study, was developed.

\section{Methods}

A group of measures were used that built on each other. These consisted of, on the one hand, continuous dermatological diagnosis and therapy (Table 4.2). On the other hand, pre-existing and behavior-influencing attitudes to the emergence and the course of the illness were determined within the framework of health education intervention $[9,15]$. An exploration of basic attitudes towards personal health and illness as well as towards the determinants of these attitudes (social environment, motivation, and so on) took place during the first consultation, which was recorded on a semi-standardized inter- view sheet. This was repeated in a modified form when each participant completed the project. Other measures included a theoretical and practical seminar on skin protection that went into the causes and forms of work-related skin disorders. This also elaborated on the skin protection measures that could be implemented. The material learned could be directly put into practice in a practical session. This meant that, for example, cutting hair whilst wearing gloves was practiced directly. All workers and barber-shop owners took part in work consultations carried out after the seminars. The causes of work-related skin disorders and ways to prevent them by applying adequate skin protection techniques were also discussed during the work consultations. A recap seminar was given for the participants at the end of the project. Difficulties encountered when putting the skin protection techniques learned into practice were discussed and solution strategies were worked out together [27]. Altogether 215 participants were enrolled in the project, and it was completed by 150 participants.

The project was evaluated according to its structure, process and results $[5,12]$. This contribution will concentrate on just the results from it. In this regard, the whole evaluation process proceeded by comparing the participants' group with an unsupervised

Table 4.2. Secondary prevention of occupational dermatoses: project phases and measures

\begin{tabular}{ll}
\hline Phase 1: & $\begin{array}{l}\text { Dermatological examination, first consulta- } \\
\text { tion, exploratory interview }\end{array}$ \\
Phase 2: & $\begin{array}{l}\text { Skin protection seminar: Theory and prac- } \\
\text { tice of skin disorders and skin protection in } \\
\text { the hairdressing trade, dermatological ex- } \\
\text { amination }\end{array}$ \\
Phase 3: & $\begin{array}{l}\text { Consultations in the participants' salons } \\
\text { Phase 4: }\end{array}$ \\
& $\begin{array}{l}\text { Final seminar/final consultation, dermato- } \\
\text { logical examination }\end{array}$ \\
\hline
\end{tabular}


control group. Moreover, an instrument of evaluation was developed for each individual measure in order to rate the level of success for each measure. Each individual investigative instrument, which will be elaborated on when the results are presented, comprised both qualitative and quantitative methods. Qualitative measures were seen as complementary to quantitative methods, especially when considering subject-oriented data [3].

\section{Results}

Subjective Attitudes and Changes in Attitude. The significance of subjective concepts to the willingness to implement preventative changes in behavior was demonstrated. Occupational socialization can influence behavioral patterns. This becomes clear from the fact that at the beginning of the project $46.7 \%$ $(n=70)$ of the participants agreed with the statement that slightly reddened or rough hands were quite normal in the hairdressing trade. By the end of the project (final consultation), only $26 \%(n=39)$ considered slightly reddened and rough hands as being "normal."

Seminars. The following results emerged from the theoretical and practical seminars (173 affected hairdressers took part in small groups). The results are based on the answers given by the participants to questionnaires filled out after each seminar. In addi- tion to the presentation of basic skin care information (which in most cases was not previously known by the participants) on the topics "skin disorders causes, forms and course of illness", "trade associations" and "skin protection", the exchange of experiences among the participants was of particular significance. Participants stressed again and again that discussing experiences with people in similar situations helped enormously (for example "no one laughed" "....it helped a great deal to see that others have the same problems..."). The practical exercises in skin protection also proved to be effective, enabling initially skeptical attitudes about carrying out some hairdressing activities with gloves to be reduced.

Overall Evaluation/Control Group. In conclusion, 150 participants completed the project, $121(81 \%)$ of them successfully, meaning that the OCD had healed to an extent that allowed them to continue to work as hairdressers. A follow-up survey of the participants carried out 3 months after completion of the project at the earliest showed that $79.9 \%$ had been able to remain in work, as opposed to a rate of $60 \%$ in the control group that had been under medical supervision alone (Fig. 4.1). A five-year follow-up recently revealed that the difference between the two groups was even more pronounced: $65 \%$ of the intervention group were still at work but only $29 \%$ of the controls remained (unpublished observations).

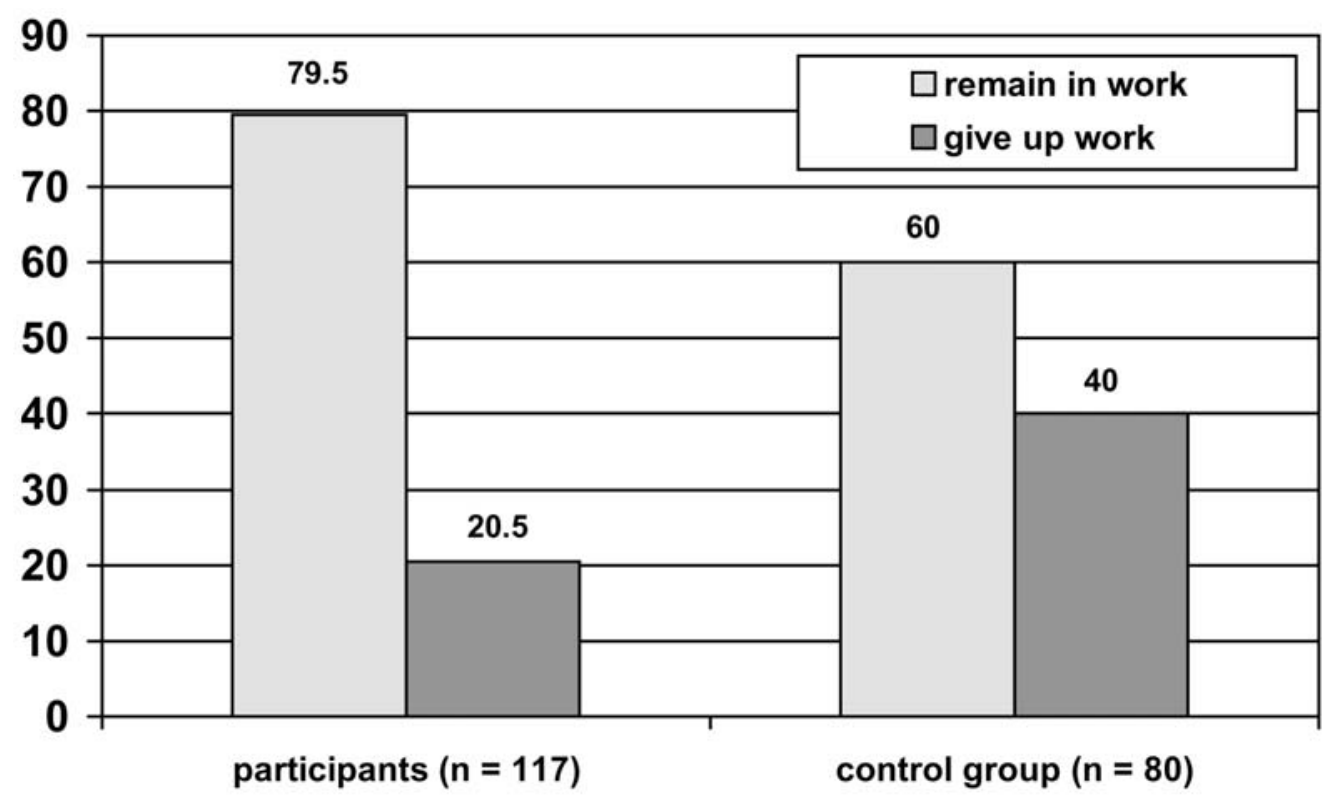

Fig. 4.1. Frequency of those remaining in work among the participants and the control group in the secondary prevention project for hairdressers, data in percent 
Workplace Interventions. During the course of the Secondary Prevention project for hairdressers, an additional workplace consultation was offered to each of the 215 participants who attended the intervention program. Therefore, workplace consultations were carried out consecutively in 103 salons, provided consent was given by the salon-owners. In these 103 salons a total of 652 hairdressers (including the participants of the intervention study, their employers and colleagues) received detailed information on the pathogenesis and epidemiology of OCD, skin protection and legal regulations. Three months after this workplace intervention, a questionnaire-based, anonymous survey amongst the participants $(n=625)$ was performed.

Skin Changes in Hairdressers. The importance of the additional - and unique - workplace intervention described above is made clear if we note the number of "hidden" cases of OCD revealed by the colleagues and employers of the hairdressers who initially attended our seminars. Of the 625 questionnaires given out, $134(21.4 \%)$ were returned. Seventy-three (54.4\%) participants stated that they had suffered from skin changes at the workplace, such as dryness, scaling, reddening, vesicles, oozing, and fissures.

Another result of this questionnaire-based study was that the use of protective gloves increased considerably after the consultations. For example, the number of workers that wore gloves when washing hair increased from $26.9 \%$ before to $51.5 \%$ after the workplace consultations. In total, $60.4 \%$ of the 134 participants claimed to have significantly improved their skin protection behavior after the workplace consultations.

\section{Secondary Prevention Project for Geriatric Nurses}

The design of the intervention study described above for hairdressers was subsequently used to investigate OCD in geriatric nurses. One hundred two affected geriatric nurses completed all elements of the intervention (see "Secondary Prevention Project for Hairdressers" section). A control group of 107 geriatric nurses was observed, who all received dermatological outpatient treatment. After 3 months, significant differences were observed, indicating that the intervention group achieved better results (Chi-square test). Ninety-six percent of the intervention group were still working as geriatric nurses, compared to $86 \%$ in the control group $(p=0.019)$. Fifty-three percent of the intervention group complained of occupational skin disorders, in comparison to $82 \%$ in the control group $(p<0.001)$. The use of gloves during patient washing increased by $22 \%$ in the intervention group while no change occurred in the control group. The results underline the advantages of this interdisciplinary dermatological and pedagogical intervention, and its transferability to other high-risk professions [16].

\subsubsection{Tertiary Prevention of Occupational Contact Dermatitis in High-Risk Professions}

A pilot-study, treating patients with severe OCD as inpatients, took place between 1994 and 1999 at the University of Osnabrück $[27,30]$. This study focused on the tertiary prevention of skin disorders, as well as on their optimized rehabilitation, with the aim of maintaining the profession.

\section{Methods}

Participants were only allowed a two-to-three-week inpatient treatment if they suffered from OCD that was resistant to standard outpatient treatments, and so job loss was a strong possibility. After the inpatient phase, treatment was continued by the local dermatologist on an outpatient basis for another two to three weeks. The employee did not work during the resulting complete intervention period of 4-6 weeks. This long work leave is recommended because a perturbed epidermal barrier in humans requires at least four weeks for complete recovery, and frequently even longer [7]. During the inpatient phase, specifically trained dermatologists offered optimized diagnostic and therapeutic strategies as well as an individualized skin protection program. These medical interventions were complemented by educational interventions on many different interacting levels. In order to keep the individual employee in the workplace, one-to-one consultations, group seminars, practical training, ergotherapy and psychological advice was offered.

In order to determine the quality of this intervention, the patients, local dermatologists and social insurance companies were interviewed one year after admittance to the hospital [27].

\section{Results}

Four hundred ninety questionnaires were sent out to the participants, of which $352(71.8 \%)$ were returned. Figure 4.2 reveals that $65.9 \%(n=232)$ of these people were able to maintain their profession, $23 \%(n=81)$ were unable to work due to OCD, $8.5 \%(n=30)$ ceased working due to other reasons, and $1.1 \% \quad(n=4)$ 
Fig. 4.2.

Tertiary prevention (inpatient program) from 1994-1999 $(n=352): 332$ (65.9\% "Yes") of the participants in the secondary prevention project for hairdressers still in their profession a year after hospitalization (23\% "No, due to OCD", $8.1 \%$ "No, due to other reasons" and $1.1 \%$ "No, for unknown reasons")

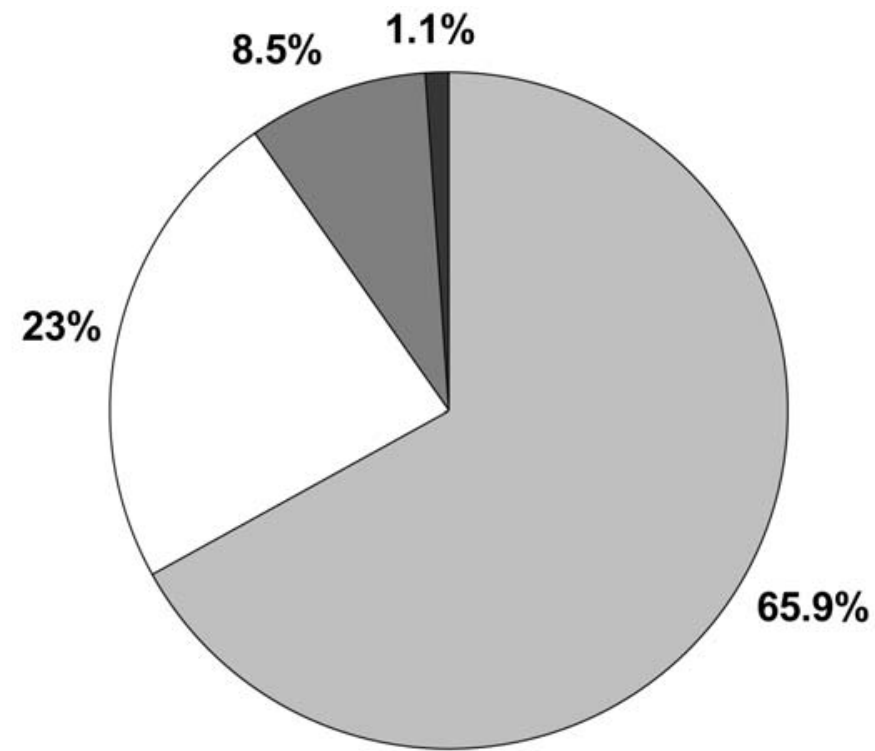

Yes $\square$ No due to OCD $\square$ No due to other reasons $\square$ No, unknown reasons stopped working for unknown reasons. While $81.3 \%$ $(n=286)$ continued using improved skin protection as advised, $6.8 \%(n=24)$ did not, and $11.9 \%(n=42)$ did not comment. Of the employees questioned, $55.7 \%(n=96)$ stated that their employer provided protective gloves, $18.2 \%(n=64)$ did not receive gloves from their employer, 9.9\% $(n=35)$ did not comment on that question, and $16.2 \%(n=57)$ of the answers could not be analyzed.

\section{Discussion}

- Primary Prevention. The above-mentioned intervention study demonstrates the importance of including skin care and protection management in the education of trainees in high-risk professions. If this is done, the incidence of OCD can be reduced significantly. The improved outcome seen for the intervention group is probably due to improved behavioral patterns resulting from the educational intervention and the supply of skin care and protective products. In conclusion, intervention proved to be effective in this context. Early introduction of trainees to prevention measures appears to be necessary to avoid bad habits which may then become a matter of routine $[11,18]$.

- Secondary Prevention. The main result from the intervention project on secondary prevention of OCD in hairdressers was that $80 \%$ of the project participants remained in work in comparison to just $60 \%$ of those in the control group. By investigating existing attitudes to the emergence of the skin disorder and the willingness to intervene autonomously in the course of the illness, it was possible to work out and successfully implement ways of motivating people to change attitudes and behavioral patterns. For example, the answers given to the question regarding the acceptance of slight skin changes as being an obligatory characteristic of the profession shed light on the significance of occupational socialization, which is partly based on old traditions [13]. The realization that we cannot expect the affected hairdressers to see a causal link between their illness and work-related skin disorders illustrates the need for theoretical material on the emergence of skin disorders in the hairdressing trade to be presented in the seminars. Explanatory and motivating strategies are two examples of such interventions [14, 21]. First of all, the teaching of theory in the seminars made it possible to achieve a positive effect by increasing knowledge about this illness. It is known from the training of patients, such as those with rheumatic diseases, that improved knowledge of the illness leads to an improvement in functional capacity. Similarly, positive therapeutic effects can be achieved by means of groups led by psychologists, supportive and clarifying conversations between patients and experts, as well as by means of an exchange of both experiences and emotional stress between the patients themselves [19]. Ehlers et al also point to the greater effectiveness of preventive measures when psychological approaches are included [6]. These remarks correspond to the results from the seminars 
carried out in the above-mentioned project. It has been known for a long time that skin disorders, and in this case hand eczema in particular, are particularly stressful (on a psychosocial level) for those affected $[25,26,29]$. In some cases, each group of seminar participants became similar to a self-help group. The educational supervision, however, facilitates professional help, for example in relation to the categorization of everyday theories and lay ideas. This therefore corresponds to the requirement that any attempts by experts to intervene by preventing or rehabilitating illness should take the psychosocial level into consideration and so pay attention to the attitudes of so-called "laymen" to health and illness.

Workplace Interventions. The role of employers in the successful implementation of preventive measures was made particularly apparent during the workplace consultations. The employer is often the only contact workers can turn to in matters of health and safety, particularly in small businesses. External reguations are more often ignored in small businesses than in larger ones, effective support from an ocupational physician often does not exist in such cases. The results from the workplace consultations add weight to the call for formalized supervision structures $[1,8,11,13]$.

The measures developed in Osnabrück have been placed in general use by the German Trade Association for the Health Service and Welfare Care, the responsible statutory accident insurer in the hairdressing trade. Between 1997 and 2002, a total of 2437 hairdressers participated in the secondary prevention program. Complete data are available for 635 hairdressers $(26 \%)$. This fraction is partly due to the fact that the evaluation is restricted to certain regions in Germany. The percentage of hairdressers with severe skin symptoms dropped from $49 \%$ at the start of the rehabilitation program to $11 \%$ after completion of the program. The proportion of hairdressers using gloves and applying skin care techniques doubled. The rehabilitation program therefore appears to be a successful way of helping hairdressers to cope with skin problems [22].

The success of the project described above underlines the need to establish further measures in the field of health and safety. In this context, health educational concepts were developed for other professions at high risk of OCD [16]. Recent studies on the prevention of OCD in apprentices in various highrisk professions, like bakers, catering trade, nurses and metalworkers, confirm these conclusions $[2,4$, $10,11]$.
Tertiary Prevention. Patients with OCD resistant to standardized outpatient care, that had been admitted to hospital, were interviewed (questionnaire) about the status of their skin and their situation at the workplace one year after hospital release. The majority of the participants had remained in their professions and practiced the advised skin care strategies. Considering the remarkable success rates of these interdisciplinary tertiary prevention programs, they should be recommended as a standard procedure whenever employees are at risk of having to leave their professions due to severe, recalcitrant OCD [30].

\section{Core Message}

It is possible to verify the efficacy of various educational programs, for example by controlled intervention studies. The results underline the necessity for even more pronounced implementation of health pedagogical interventions in joint interdisciplinary initiatives for prevention of OCD. Of course, health pedagogical measures must be evidence-based; continuous quality management and long-term evaluations are crucial.

\section{References}

1. Agner T, Held E (2002) Skin protection programmes. Contact Dermatitis 47:253-256

2. Bauer A, Kelterer D, Bartsch R, Pearson J, Stadeler M, Kleesz P, Elsner P, Williams H (2002) Skin protection in bakers' apprentices. Contact Dermatitis $46: 81-85$

3. Berg M (1991) Evaluation of a questionnaire used in dermatological epidemiology. Discrepancy between selfreported symptoms and objective signs. Acta Derm Venereol (Stockh) 156:13-17

4. Berndt U, Hinnen U, Iliev D, Elsner P (2000) Hand eczema in metalworker trainees - an analysis of risk factors. Contact Dermatitis 43:327-332

5. Donabedian A (1968) Promoting quality through evaluating the process of patient care. Med Care 6:181-202

6. Ehlers A, Gieler U, Stangier U (1995) Treatment of atopic dermatitis: a comparison of psychological and dermatological approaches to relapse prevention. J Consult Clin Psychol 63:624-635

7. Fartasch M (1995) Human barrier formation and reaction to irritation. In: Elsner P, Maibach HI (eds) Irritant dermatitis. New clinical and experimental aspects. Current problems in dermatology. Karger, Basel, pp 95-103

8. Geraut C, Tripodi D (2002) Prevention of occupational dermatitis. Rev Prat 52:1446-1450

9. Graziani C, Rosenthal MP, Diamond JJ (1999) Diabetes education program use and patient-perceived barriers to attendance. Family Med 31:358-363 
10. Held E, Wolff C, Gyntelberg F, Agner T (2001) Prevention of work-related skin problems in student auxiliary nurses: an intervention study. Contact Dermatitis 44:297-303

11. Held E, Mygind K, Wolff C, Gyntelberg F, Agner T (2002) Prevention of work related skin problems: an intervention study in wet work employees. Occup Environ Med 59: 556-561

12. Heron RJL (1997) Worker education in the primary prevention of occupational dermatoses. Occup Med 47: 407-410

13. Jensen LK, Kofoed LB (2002) Musculoskeletal disorders among floor layers: is prevention possible? Appl Occup Environ Hyg 17:797-806

14. Kalimo K, Kautiainen H, Niskanen T, Niemi L (1999) 'Eczema school' to improve compliance in an occupational dermatology clinic. Contact Dermatitis 41:315-319

15. Kanzler MH, Gorsulowsky DC (2002) Patients' attitudes regarding physical characteristics of medical care providers in dermatologic practices. Arch Dermatol 138: 463-466

16. Klippel U, Schürer NY, Schwanitz HJ (2004) Sekundäre Individualprävention von Handekzemen in der Altenpflege: Perspektive der Gesundheitspädagogik. Derm Beruf Umwelt 52:106-112

17. Lee A, Nixon R (2001) Occupational skin disease in hairdressers. Australas J Dermatol 42:1-6

18. Löffler H, Effendy I (2002) Prevention of irritant contact dermatitis. Eur J Dermatol 12:4-9

19. Lorish CD, Boutaugh ML (1997) Patient education in rheumatology. Curr Opin Rheumatol 9:106-111

20. Napalkov N (1995) The role of the World Health Organization in promoting patient education with emphasis on chronic diseases. In: Assal J-P, Golay A, Visser AP (eds) New trends in patient education. Elsevier, Amsterdam, pp 5-7

21. Nevitt GJ, Hutchinson PE (1996) Psoriasis in the community: prevalence, severity and patients beliefs and attitudes towards the disease. Br J Dermatol 135:533-537

22. Nienhaus A, Rojahn K, Skudlik C, Wulfhorst B, Dulon M, Brandenburg S (2004) Sekundäre Individualprävention bei FriseurInnen mit arbeitsbedingten Hauterkrankungen. Gesundheitswesen 66:759-764

23. Riehl U (2000) Interventionsstudie zur Prävention von Hauterkrankungen bei Auszildenden des Friseurhandwerks. Rasch, Osnabrück

24. Rycroft RJG (2001) Occupational contact dermatitis. In: Rycroft RJG, Menné T, Frosch PJ, Lepoittevin JP (eds) Textbook of contact dermatitis, 3 rd edn. Springer, Berlin Heidelberg New York, pp 555-580

25. Schmid-Ott G, Jaeger B, Kuensebeck HW, Ott R, Lamprecht F (1996) Dimension of stigmatisation in patients with psoriasis in a "Questionnaire on experience with skin complaints”. Dermatology 193:304-310

26. Schwanitz HJ (1988) Atopic palmoplantar eczema. Springer, Berlin Heidelberg New York

27. Schwanitz HJ, Riehl U, Schlesinger T, Bock M, Skudlik C, Wulfhorst B (2003) Skin care management: educational aspects. Int Arch Occup Environ Health 76:374-381

28. Schwanitz HJ, Uter W (2000) Interdigital dermatitis: sentinel skin damage in hairdressers. Br J Dermatol 142: 1011- 1012

29. Schwanitz HJ, Wulfhorst B (2000) Workers education. In: Kanerva L, Elsner P, Wahlberg JE et al (eds) Handbook of occupational dermatology. Springer, Berlin Heidelberg New York, pp 441-443

30. Skudlik C, Schwanitz HJ (2004) Tertiary prevention of occupational skin diseases. JDDG 2:424-433
31. Uter W, Pfahlberg A, Gefeller O, Schwanitz HJ (1998) Prevalence and incidence of hand dermatitis in hairdressing apprentices: results of the POSH study. Prevention of occupational skin disease in hairdressers. Int Arch Occup Environ Health 71:487-492

32. Van der Walle HB, Brunsveld VM (1994) Dermatitis in hairdressers (I). The experience of the past four years. Contact Dermatitis 30:217-221

33. World Health Organization (WHO) (1986) Ottawa Charta for Health Promotion. WHO, Geneva

34. Wulfhorst B (2002) Theorie der Gesundheitspädagogik. Legitimation, Aufgabe und Funktionen von Gesundheitserziehung. Reihe Grundlagentexte Gesundheitswissenschaft. Juventa, Weinheim

\subsubsection{The Swiss Experience: www.2hands.ch}

\section{Daniel Perrenoud, Thierry Gogniat, William Olmstead}

\subsubsection{Introduction}

The idea for a national campaign for the prevention of work-related contact dermatitis began in 1997 when informal conversations with teachers in professional training schools were initiated. In Switzerland about a quarter of all occupational disability claims handled by the Swiss Accident Insurance Fund (SUVA) involve skin disease, and more than half of these are hand-related. This being the case, it seemed appropriate to begin with those most at risk: apprentices.

We started with some basic ideas which we modified as our campaign evolved. The campaign was to be based on a kit that would be a complete self-contained unit that would place the teacher at the center of the presentation.

We distributed our first kits in September 1999. By early 2000, 300 kits had been distributed to teachers of apprentices all over Switzerland. Since 2003, all our material has been made available on the internet.

\subsubsection{The Beginning}

We started by studying the material available.

We found illustrations in the style familiar to all medical students, showing the complex anatomy of the skin of a hand. We also found a number of professionally-made videos from Sweden, each focusing on one particular problem by using a short story involving different groups of young people.

Neither of these approaches were suited to our purposes. The drawback we found was that they were too complex for the audience we were targeting. 
We also realized that our audience of apprentices and young workers might have negative reactions to overly formal academic presentations. In addition, we wanted the teachers to be the presenters - the conduit through which our material would be delivered.

\subsubsection{Developing New Material}

To break through the negative expectations of "just another lecture on hand care," we decided to start our presentation with a very lively MTV-style music video.

This two-and-a-half-minute video was about hands, but there was only music and mostly unintelligible voices - a disco scene.

The result we hoped for was that the audience would be intrigued and involved - they would ask themselves "What is this? It's clearly not a typical documentary-style presentation!". This was one of our basic ideas: to establish a rapport with the audience.

When the video stops the teacher takes center stage. The teacher presents a series of overheads, adapted to the audience. Overheads were preferred to slides. With overheads, the teacher looks at the audience and is the messenger. With a slide presentation the presenter fades into the background in a usually dimly-lit room.

This was another of our basic ideas: to make sure that it's the teacher who delivers the information. Our whole kit is designed to ensure this - it gives the teacher everything required.

Our kit includes 23 transparencies accompanied by a set of notes with suggestions for discussion and in-depth treatment, as well as a great deal of supplementary material.

We created many graphic images. Two typical ones are reminiscent of Malten's famous review paper, Thoughts on Irritant Contact Dermatitis, published in Contact Dermatitis in 1981 [1]. We show the mechanism of skin irritation and then distinguish between acute and cumulative irritation (Figs. 4.3, 4.4).

The contrast is made between viruses and allergens, in terms of their relationship with the immune system. Different professions and their specific dangers are profiled in turn. Irritation is then presented as opening the door to allergy.

The point is then made that once an allergy happens the young apprentice may have to change professions.

All this is presented as graphically and as simply as possible (Fig. 4.5). We wanted to make a presentation that would be very graphic in nature and thus something that a nonspecialist teacher could comfortably present with just a few supporting notes, and whose message an unsophisticated audience could grasp. Aside from simplicity, another advantage of a graphically-oriented presentation is the ease with which it can be adapted to other languages.

\subsubsection{A Graphical Course for the Workplace}

After we had already started our first campaign, we were asked by the Swiss Accident Insurance Fund (SUVA) to develop a graphic educational course to be used in the metalworking industry workplace [2]. This required that we simplify the graphic message

Fig. 4.3.

Skin irritation allows environmental chemicals to penetrate the skin and induce inflammation

\section{the skin, living tissue}

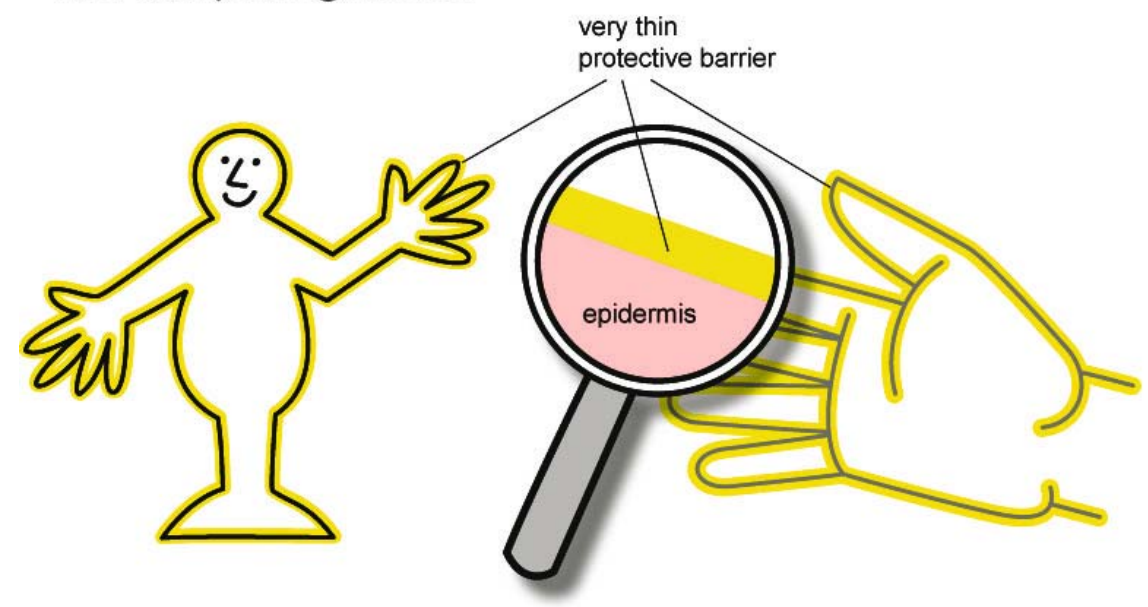


Fig. 4.4.

Acute and cumulative irritation result in comparable effects on the skin, however, weak or moderate irritants are frequently not recognized as harmful

\section{skin irritation}

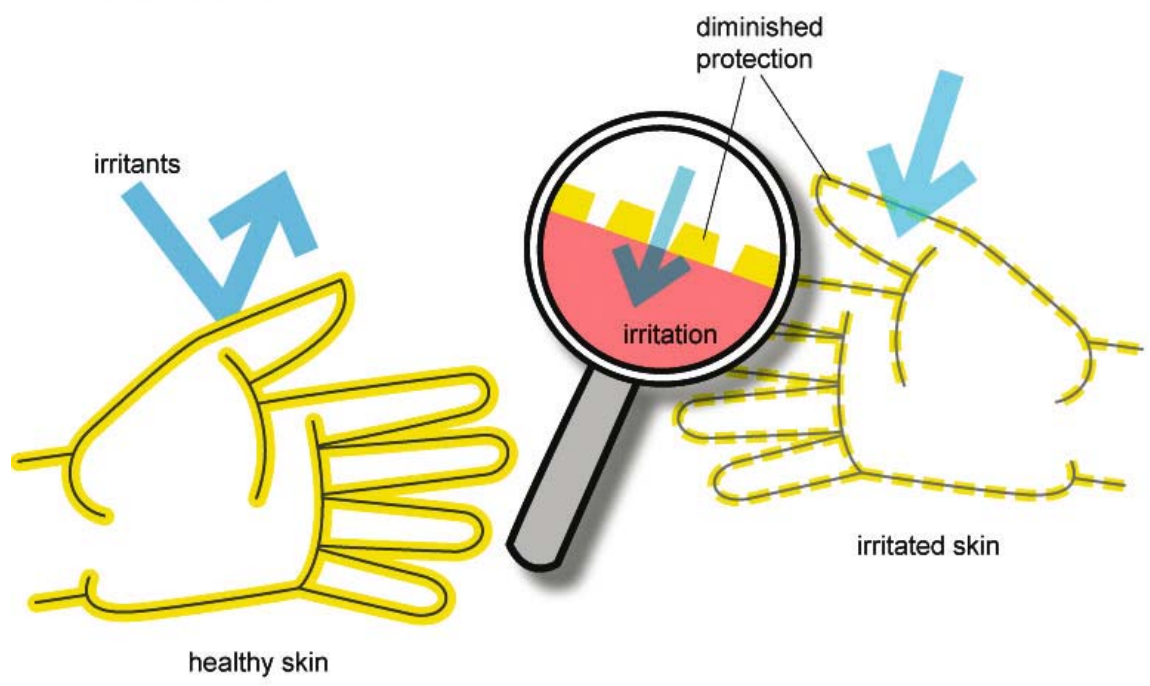

the 2 kinds of irritation

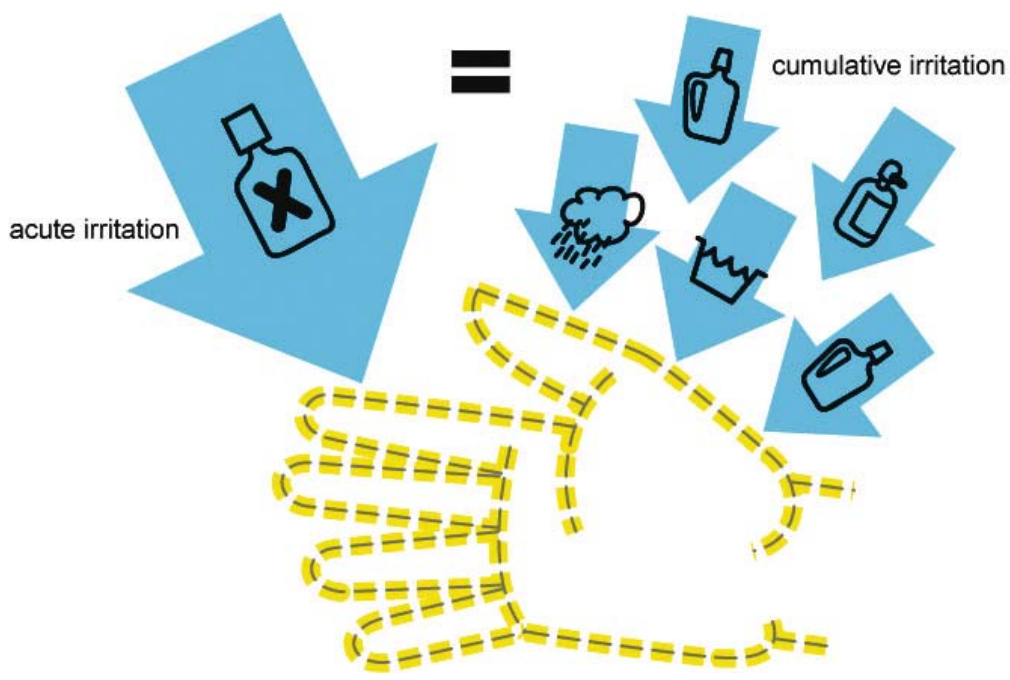

Fig. 4.5.

A good drawing is worth a thousand words: keep the message simple! even further - the text was completely removed. This illustrates a basic principle we follow: adapt the presentation of the information to the audience and the circumstances.

Lastly, we tried to ensure that what we produced would be used fully: we made a complete kit. A point now about the kit being a complete solution. We offer information in the hope of changing attitudes and eventually behavior. We think that it's important to actually practice the desired behavior in the classroom or at the workplace sessions. Therefore, we give each participant a sample of handcream and then instruct them on how to ensure that no areas of the skin are missed. Just like any other prophylactic, it must be used each time you are exposed, and used properly.

We put all of the material into a box that can be easily transported, stored, and even mailed through the regular post.

Teachers rapidly embraced the kit thanks to its simplicity and ease of use. Feedback was also gratifyingly high among those outside the teaching profession per se: health professionals, safety engineers and others involved in skin disease prevention, even outside Switzerland. 


\subsubsection{The 2hands.ch Website}

Since 2003, all of our material has been available on the Internet. As a matter of fact, we took the opportunity to redesign both the course and the educational text material completely. We also translated all of the material into English, making the content of our website available in four languages. We also introduced new themes, such as "How to find the right gloves for the right occupation". This chapter was deliberately an easy-to-use tool for end users: students, teachers, workers, housewives, and any person interested in skin care and protection. We developed it with the support of, and in close co-operation with, the SUVA and its department that sells safety products, called Sapros, online [4].

At present, occupational schools that are using our kit are now switching to using our material in electronic format; it is available in Acrobat PDF format on our website [3]. Putting the material on the Web increased the interest from Swiss industry in our material on the prevention of skin disease in the workplace. On average, our website currently gets over 120 hits daily - well beyond our initial expectations.

\subsubsection{Making the Knowledge Available Where Needed}

We close with a quote from an article called Strong Inference [5]: "We speak piously of taking measurements and making small studies that will 'add another brick to the temple of science'. Most such bricks just lie around the brickyard."

In other words, aside from doing good research and publishing the results, aside from designing good education material and prevention campaigns, aside from developing better protective creams and gloves, we must take the extra step of fulfilling our social responsibility to ensure that all of the material ("all of the bricks") - are used to make something useful to the world at large.

Acknowledgements. We warmly thank Dr Hanspeter Rast, Dr Rudolf Schütz, Ms Désirée Schibig and all their colleagues at the SUVA in Lucerne, who have believed in and continuously supported our work since the beginning.

\section{References}

1. Malten KE (1981) Thoughts on irritant contact dermatitis. Contact Dermatitis 7:238-247

2. Suva (2005) Module d'apprentissage Protection de la peau. Notice de formation pour l'industrie de la métallurgie. Suva, Lucerne (réf 88803 , see http://www.suva.ch)

3. Perrenoud D, Gogniat T (2005) 2hands.ch websites.

(See http://www.2hands.ch, http://www.2mains.ch, http://www.2haende.ch, and http://www.2mani.ch)

4. Sapros (2005) Sapros homepage.

See (http://www.sapros.ch)

5. Platt JR (1964) Strong inference. Science 146:347-353

\subsubsection{The Danish Experience: Prevention of Skin Problems in Wet Work Employees}

\section{Elisabeth Held, Tove Agner}

In Denmark, hand eczema (HE) is the most commonly recognized occupational disease, accounting for about $40 \%$ of all recognized cases [1]. Wet work is considered to be the most important risk factor for the development of chronic HE. It is important to prevent HE, since the disease often becomes chronic or even disabling. Important preventive measures include exposure control, employee education and use of personal protective equipment such as gloves and moisturizers. Intervention studies in the workplace are, however, necessary to determine the effectiveness of such preventive measures.

\subsubsection{Intervention Studies}

Using the concept of an intervention study, it is possible to demonstrate whether a given intervention is possible and whether it will have the intended effect [2]. Employee education is an important preventive measure and should preferably result in increased knowledge about the function of the skin, awareness of symptoms due to occupational hazards and an understanding of managing hazards and the correct use of moisturizers and gloves. Organizational support is, however, also important, and written policies on work procedures should also be implemented at the workplace [3].

In the following, the experiences gained from some Danish intervention programs will be discussed. Two intervention studies were conducted with wet work employees: one in student auxiliary nurses (study I) [4] who were having their first apprentice period, and one study in wet work employees in nursing homes (study II) [5]. An intervention 
group and a matched control group were included in both studies, and the intervention group was exposed to an educational program including a skin protection program before or during the intervention period. The educational program provided information about normal and diseased skin, leading to increased awareness and early recognition of skin symptoms due to wet work. One of the prerequisites was for the participants to understand recommendations regarding wet work procedures (skin protection program). The skin protection program [6] was a series of practical instructions about skin protection that included updated evidence-based recommendations about wet work procedures and the use of protective measures (for ten actions that can help prevent hand eczema, refer to Chap 19).

\subsubsection{Student Auxiliary Nurses (I)}

The intervention group included 61 students (three classes) from one school and the control group included 46 students (three classes) from another school, both located in the County of Copenhagen, and they were both followed during the first ten weeks of their first practical training in county hospitals. The intervention group was given an educational program just before the students had their first practical training. In each intervention class, a $2 \times 2 \mathrm{~h}$ course was given with the sessions separated by an interval of 14 days. The course was conducted by two teachers and included an informative video and a booklet, which students were asked to read in between the two teaching sessions. The educational program was an interactive dialog based on the student's own experiences of wet work and included an introduction to the physiology of normal and diseased skin and to allergic and irritant contact dermatitis. As part of the intervention, the students were exposed to the evidence-based skin protection program and all participants in the intervention group were given a moisturizer ( $100 \mathrm{~g})$, with a documented positive effect on irritant contact dermatitis $[7,8]$.

To evaluate the participants, they were each given a questionnaire to fill in, a clinical hand examinations and patch testing, and their transepidermal water loss (TEWL) was measured, both before and after the 10 weeks of practical training.

Of the 107 student auxiliary nurses included in the study, 13 participants dropped out during the training period (seven in the intervention group and six in the control group).

After the practical training, where the student auxiliary nurses were exposed to wet work, there was a significant increase in the number of participants with skin problems $(p<0.0005)$ as judged by clinical examination ( $48 \%$ in the intervention group and $58 \%$ in the control group; $p>0.05$ ). Aggravation of skin problems was associated with having doctor-diagnosed atopic dermatitis (odds ratio: 4.89 , confidence interval: 1.16-20.64, $p=0.027)$. Three students with atopic dermatitis (all belonging to the control group) developed severe vesiculous hand eczema during the training. Patch testing revealed that $25 \%$ of those in the intervention group and $38 \%$ of those in the control group had nickel allergies $(p=0.35)$.

A significant increase in TEWL, indicating a defect in the skin barrier function, was seen in the control group but not in the intervention group after ten weeks of practical training. High basal TEWL was not associated with occurrence of skin symptoms during the practical training, as evaluated by clinical examination.

\subsubsection{Wet Work Employees (Nursing Homes) (II)}

Three hundred seventy-five wet-work employees were included in a prospective randomized controlled trial, allocated to either intervention $(n=207)$ or control $(n=168)$. The study period was 5 months. The study population was recruited from employees (nursing, kitchen and cleaning) of seven old peoples homes in the City of Copenhagen. Three nursing homes were chosen at random for the intervention group and four for the control group. A formalized educational program was given to a team of frontline employees (10-20 persons) called the "participatory team" in each intervention workplace. This team included employees willing to undergo an educational program and willing to teach and instruct other employees. The team included at least one person from management, one from the local safety board, and one from each working sector (nursing, kitchen and cleaning). After the training the participatory team passed the information on to their colleagues. As part of the intervention, a skin protection policy (including written instructions) was established in each workplace. Moisturizers $[7,8]$ and cotton gloves were freely available for all employees.

The intervention and control groups completed questionnaires on behavior and symptoms and underwent clinical examination of their hands before and after the five-month period, as well as answering a test quiz.

Three-quarters $(156 / 207)$ of the intervention group and slightly more $(78 \% ; 131 / 168)$ of the control group completed the study. No difference was found between the intervention and the control group at 
baseline with respect to clinical symptoms or behavior. Evaluation after the five-month intervention period revealed significantly more knowledge of skin protection techniques in the intervention group as compared to the control group ( $p=0.003$ ), a significant change in wet work behavior in the intervention group but not in the control group, and significantly fewer skin symptoms as evaluated clinically for the intervention group $(p<0.0001)$ but not for the control group $(p=1.00)$. The significant change in behavior included fewer hours spent with wet hands, fewer rings worn on fingers, and increased use of cotton gloves. Ninety percent of the participants in the intervention group agreed that they had received information about good skin protection during the 5 months of intervention. Ninety-seven percent of the employees had received moisturizers that were freely provided, and $79 \%$ had received cotton gloves. Seventy-four percent $(116 / 156)$ of the intervention group and $55 \%(72 / 131)$ of the control group accepted patch testing. Nickel allergy was confirmed in $29 \%$ of the patch-tested participants in the intervention group and in $32 \%$ of the control group ( $p>0.05)$.

\subsubsection{Discussion}

Study I confirmed that atopic dermatitis is a significant risk factor for skin problems or aggravation of already existing skin problems when exposed to wet work for a ten-week period. This is supported by numerous previous findings [9-11], and it highlights the fact that a history of atopic dermatitis and wet work are often noncompatible factors. Some studies have shown that skin irritation often occurs early in the professional career $[12,13]$. The present study confirms this, indicating that clinical examination of the hands (pre-employment screening) may be advantageous for trainees. In study I, that included student auxiliary nurses, the clinical examination did not reveal any statistically significantly difference between the intervention group and the control group after the ten-week period of training. This was either a true negative finding or one related to the small number of participants included. A possible explanation is that the intervention strategy used in this study targeted at an individual level, so no organizational support was included. Bioengineering measuring methods for predicting skin susceptibility have been found to be useful in experimental studies, but their relevance in field studies is still debated. Some experimental studies have shown that high baseline TEWL may be a good predictor of skin susceptibility $[14,15]$. Significant increases in TEWL in the exposed skins of the student auxiliary nurses were seen in the control group after 10 weeks of training, perhaps indicating subclinical skin irritation, but baseline TEWL failed to predict the development of skin symptoms.

In study II, including wet work employees from nursing homes, the behavioral changes prescribed in the skin protection program for the intervention group were achieved for some measurable activities, such as an increased use of cotton gloves, and fewer hours spent with wet hands. The success of the intervention may be related to the fact that the behavioral changes were limited to small practical changes during work hours and that positive changes in skin symptoms due to altered behavior can be followed closely, thereby motivating the employee to continue the skin protection program. A methodological problem in clinical studies is that subjects suffering from skin problems are more likely to use protective measures and preventive measures will then be associated with the outcome variable hand eczema, as stated by Diepgen and Coenraads [16].

In the field of prevention of work-related HE, particular attention has been paid to the effect of moisturizers. In the intervention studies presented here, a moisturizer that had proved efficient for treating irritant skin reactions in experimental studies was available to all participants in the intervention group. In both studies, no differences were observed in the use of moisturizer between the intervention and the control group, neither before nor after the intervention. Most of the participants (93\%) were already using a moisturizer before they began the study (II). A similar high percentage of moisturizer use has been found in other studies in health care workers [13].

In both intervention studies (I and II), a high percentage $(>25 \%)$ of the participants had nickel allergy (confirmed by patch testing), but any statistically significant correlation between nickel allergy and skin problems/HE was not confirmed.

Participatory action research implies that the employees take an active role in all phases of the intervention [2]. This approach has proven effective in the prevention of musculoskeletal disorders among health care workers [17]. A similar method was used in study II, where a group of frontline employees first underwent a training program, then developed written procedures and subsequently introduced the messages to their colleagues.

In conclusion, an educational program, including an evidence-based skin protection program with recommendations on wet work procedures and the use of preventive measures, was tested in student auxiliary nurses and in wet work employees. In study II, the intervention had a positive influence on wet work behavior, on knowledge, as well as on clinical skin 
problems, whereas study I failed to show any statistically significantly influence on the number of clinical skin problems. In study II, the focus was on prevention at both the individual and the organizational level. Both strategies are important, but intervention at an organizational level ("policy making") ensures that preventive measures are integrated as a part of the daily routine after the intervention period has stopped, ensuring a continuous learning process [18].

It is important that recommendations in skin protection programs undergo evaluation at regular intervals in order to include the latest evidence from both clinical and experimental studies.

\subsubsection{Important Messages}

Intervention at the workplace should improve employee knowledge, wet-work behavior and clinical skin conditions.

- Involvement at an organizational level is necessary to obtain successful prevention.

- Intervention studies are necessary to document the effects of preventive measures.

\section{References}

1. National Board of Industrial Injuries in Denmark (2005) Website (see http://www.ask.dk)

2. Kristensen TS (2000) Workplace intervention studies. Occup Med 15:293-305

3. Goldenhar LM, Schulte PA (1994) Intervention research in occupational health and safety. J Occup Med 36:763-775

4. Held E, Wollf C, Gyntelberg F, Agner T (2001) Prevention of work-related skin problems in student auxiliary nurses. An intervention study. Contact Dermatitis 44:297-303
5. Held E, Mygind K, Wollf C, Gyntelberg F, Agner T (2002) Prevention of work related skin problems. An intervention study in wet-work employees. Occcup Environ Med 59: 556-561

6. Agner T, Held E (2002) Skin protections. Contact Dermatitis $47: 253-256$

7. Ramsing DW, Agner T (1997) Preventive and therapeutic effects of a moisturizer. An experiment study on human skin. Acta Derm Venereol (Stockh) 77:35-37

8. Held E, Agner T (1999) Comparison between two test models in evaluating the effect of a moisturizer on irritated human skin. Contact Dermatitis 40:261-268

9. Brisman J, Meding B, Järvholm B (1998) Occurrence of self reported hand eczema in Swedish bakers. Occup Environ Med 55:750-754

10. Rystedt I (1985) Hand eczema and long-term prognosis in atopic dermatitis (thesis). Acta Derm Venereol (Stockh) 117:1-59

11. Tacke J, Schmidt A, Fartasch M, Diepgen TL (1995) Occupational contact dermatitis in bakers, confectioners and cooks: a population-based study. Contact Dermatitis 33: $112-117$

12. Bauer A, Bartsch R, Stadeler M, Schneider W, Grieshaber R, Wollina U, Gebhardt M (1998) Development of occupational skin diseases during vocational training in baker and confectioner apprentices: a follow-up study. Contact Dermatitis 39:307-311

13. Hansen KS (1983) Occupational dermatoses in hospital cleaning woman. Contact Dermatitis 9:343-351

14. Pinnagoda J, Tupker RA, Coenraads PJ, Nater JP (1989) Prediction of susceptibility to an irritant response by transepidermal water loss. Contact Dermatitis 20:341-346

15. John SM, Uter W, Schwanitz HJ (2000) Relevance of multiparametric skin bioengineering in a prospectively-followed cohort of junior hairdressers. Contact Dermatitis 43:161-168

16. Diepgen TL, Coenraads PJ (1997) Inflammatory skin diseases II: contact dermatitis. In: Williams HC, Strachan DP (eds) The challenge of dermato-epidemiology. CRC, Boca Raton, Fla., pp 145-160

17. Evanoff BA, Bohr PC, Wolf LD (1999) Effects of a participatory ergonomics team among hospital orderlies. Am J Ind Med 35:358-365

18. Ford JK, Fisher S (1994) The transfer of safety training in work organizations: a systems perspective to continuous learning. Occup Med 9:241-259 